\title{
An overview on silica aerogels synthesis and different mechanical reinforcing strategies
}

\author{
Hajar Maleki *, Luisa Durães, António Portugal \\ CIEPQPF, Department of Chemical Engineering, Faculty of Sciences and Technology, University of Coimbra, Rua Sílvio Lima, 3030-790 Coimbra, Portugal
}

\section{A R T I C L E I N F O}

\section{Article history:}

Received 2 May 2013

Received in revised form 2 October 2013

Available online 22 November 2013

\section{Keywords:}

Silica aerogels;

Sol-gel;

Mechanical reinforcement;

Hybrid materials

\begin{abstract}
A B S T R A C T
Silica aerogels are lightweight and highly porous materials, with a three-dimensional network of silica particles, which are obtained by extracting the liquid phase of silica gels under supercritical conditions. Due to their outstanding characteristics, such as extremely low thermal conductivity, low density, high porosity and high specific surface area, they have found excellent potential application for thermal insulation systems in aeronautical/aerospace and earthly domains, for environment clean up and protection, heat storage devices, transparent windows systems, thickening agents in paints, etc. However, native silica aerogels are fragile and sensitive at relatively low stresses, which limit their application. More durable aerogels, with higher strength and stiffness, can be obtained by proper selection of the silane precursors, and constructing the silica inorganic networks by compounding them with different organic polymers or different fiber networks. Recent studies showed that adding flexible organic polymers to the hydroxyl groups on the silica gel surface would be an effective mechanical reinforcing method of silica aerogels. More versatile polymer reinforcement approach can be readily achieved if proper functional groups are introduced on the surface of silica aerogels and then copolymerized with appropriate organic monomers. The mechanical reinforced silica aerogels, with their very open texture, can be an outstanding thermal insulator material for different industrial and aerospace applications.

This paper presents a review of the literature on the methods for mechanical reinforcing of silica aerogels and discusses the recent achievements in improving the strength and elastic response of native silica aerogels along with cost effectiveness of each methodology.
\end{abstract}

(c) 2013 Elsevier B.V. All rights reserved.

\section{Introduction}

Silica aerogels are materials with unique properties such as high specific surface area (500-1200 $\left.\mathrm{m}^{2} \cdot \mathrm{g}^{-1}\right)$, high porosity (80-99.8\%), low density $\left(\sim 0.003-0.5 \mathrm{~g} . \mathrm{cm}^{-3}\right)$, low thermal conductivity $(0.005-0.1 \mathrm{~W} /(\mathrm{mK}))$, ultra low dielectric constant $(k=1.0-2.0)$ and low index of refraction $(\sim 1.05)[1,2]$. Due to their such unusual characteristics, much attention has been given to silica aerogels in recent years for their use in several technological applications including Cherenkov radiators in particle physics experiments [3] and thermal insulation materials for skylights and windows [4]. Silica aerogels have also been used for making heat storage devices used in window defrosting and as acoustic barrier materials [5]. Other aerogels have been demonstrated as battery electrodes [6], catalyst supports [7], and oxygen and humidity sensors [8] and adsorbents for environmental clean-up [9] due to their large internal surface areas and facile changing of their surface chemistry. The low values of thermal conductivity and the very low density make silica aerogels attractive

\footnotetext{
* Corresponding author. Tel.: +351910156 989; fax: +351239798703. E-mail address: hajar@eq.uc.pt (H. Maleki).
}

materials for a number of aerospace applications. One example involves insulation around the battery packs in the Mars Sojourner Rover to protect its electronic units [10]. More robust and flexible aerogels are being considered to insulate extra-vehicular activity (EVA) suits for future manned missions to Mars [11]. Aerogel composites are the only materials that come close to meet the requirements for EVA suit insulation [12]. Robust aerogel composites are also considered as insulation materials of inflatable decelerators for entry, descent, and landing (EDL) applications for future space missions on Mars [13].

It should be noted that aerogel applications in space are not all limited to thermal insulation. Indeed, silica aerogels can also be applied to collect aerosol particles [14], to protect space mirrors or to design tank baffles $[15,16]$. However, these applications of silica aerogels have been restricted because of their extreme fragility and poor mechanical properties and hygroscopic nature [17]. Therefore, with the purpose of expanding the application range of aerogels, while fully retaining their outstanding properties, mechanically more robust aerogels are needed.

Different methods have been explored to improve the mechanical properties of silica aerogels such as structural reinforcement using flexible silica precursors in silica gel backbone [18-21], conformal 
coating of silica backbone via surface cross-linking with a polymer [22-26], and dispersing carbon nanofibers in the initial sol of silica aerogel [27]. In principle, to improve flexibility or elastic recovery in silica aerogels, it is required either to include organic linking groups in the underlying silica structure or to cross-link the skeletal gel framework through surface silanol groups by reacting them with monomers/polymers.

Since the silica aerogels consist of silica particles that are connected to each other via only $\mathrm{Si}-\mathrm{O}-\mathrm{Si}$ stiff bonds, the compounding of the silica aerogel with polymer leads to an increase of the connection points between the silica particles, with the formation of extra strong $-(\mathrm{C}-\mathrm{C}-)$ covalent bonds between these particles [28]. Therefore, such methodology leads to an increase of the strength of the reinforced silica aerogels over native silica aerogels [29]. Thus, the objective of such compounding with organic polymers is to provide an aerogel with good compressive strength to be able to adapt to the design of components and to adsorb the energy involved in shock compressions [14,15,30,31]. However, manufactured aerogels are not strong enough to be reshaped and must be casted to the final forms during synthesis and processing [32]. But, it has been proven that elasticity/flexibility can be significantly enhanced in non cross-linked aerogels by altering the chemical nature of the silica backbone. For example, for TMOS/BTMSH-derived aerogel, with densities bellow $0.06 \mathrm{~g} . \mathrm{cm}^{-3}$, it was possible to bend by $50^{\circ}$ the material without breaking it [33]. Additionally, Kramer et al. [34] demonstrated that an addition of up to $20 \%$ (w/w) poly(dimethylsiloxane) in (TEOS)-derived aerogels resulted in rubbery behavior with up to $30 \%$ recoverable compressive strain. Shea and Loy [35] have developed hybrid aerogels from bridged polysilsesquioxanes, using building blocks comprised of organic bridging groups attached to two or more trialkoxysilyl groups via nonhydrolyzable carbon-silicon bonds. All of these methods proved to be different ways of tuning mechanical properties to the application requirements.

As it is indicated by Fricke [36] and Pekala et al. [37], due to the tradeoff between mechanical properties (e.g. Young's modulus or maximum strength) of silica aerogels with their density, the most straightforward methods of mechanical reinforcing of silica aerogels result in increasing the density and therefore increasing the thermal conductivity [38-40]. This is caused by the increase of the total amount of material used for the production of the gel matrix, due to the need of increasing the total number of connection points within the silica aerogel. The most recent achievements involve the preparation of aerogels with approximately three order of magnitude improvement in their maximum compression strength at break with only doubling the density and thermal conductivity [29]. Therefore, the purpose of this review is to provide an overview about versatile methods to impart higher strength or stiffness to silica aerogel monoliths with minimum increase of their density and thermal conductivity.

General physical and chemical issues involved in the synthesis of silica gels were explained in books $[41,42]$. Additionally, many reviews on aerogels, with particular focus on silica aerogels, have already been published [1,43-47], which give a more specific and complete description about the aerogels' processing, properties and applications. For the purpose of strengthening the mechanical properties of silica aerogels, different possible strategies of surface chemistry modification of aerogels, followed by compounding their surfaces with appropriate organic polymers, namely epoxide [48,49], polyurea [50], polyurethane [33,51], polyacrylonitrile [22], and polystyrene [52,53], are reviewed by Leventis et al. [26,54], and more recently by Meador et al. [29,32].

The present review is composed by two parts: firstly, a general history of silica aerogels with chemistry beyond their methods of synthesis and the principles of the drying techniques is given; secondly, an extensive study of very recent published works about the development of silica aerogels with improved mechanical properties is presented, with particular emphasis on recent advanced methods for preparing class II hybrid polymer-silica aerogels. The main objective is to review the possible physical and chemical existing methodologies to improve the mechanical properties of silica aerogels, which were not under scope of studying by the previous authors. Additionally, the present review surveys the use of different kinds of nanofiber networks, including polymeric [55-57], ceramic $[58,59]$ and carbon nanofibers [58], in order to develop the free standing silica with improvements on skeletal maintenance of native silica or even polymer reinforced aerogels. Finally, the future trends for development of flexible and bendable hybrid thin sheets of silica aerogels are addressed, being these materials suitable for folding or wrapping around different space assemblages, such as around the electronics and battery packs in the Mars Sojourner Rover [10]. Moreover, the development of smart silica aerogels using shape memory polymers [60] is also mentioned as a major future development and is described in the last part of the present review.

\section{Sol-gel chemistry}

Generally, a nanostructured solid network of silica is formed as a result of a hydrolysis and condensation process of the silica precursor molecules, in which siloxane bridges $(\mathrm{Si}-\mathrm{O}-\mathrm{Si}$ ) are formed. Such reactions are equivalent to a polymerization process in organic chemistry, where bonds between the carbon atoms of organic precursors lead to linear chains or branched (cross-linked) structures [61].

The manufacturing process to form silica aerogels comprises two steps: the formation of a wet gel by sol-gel chemistry, and the drying of the wet gel. Originally, silica wet gels were made by Kistler in the early 1930s $[62,63]$ through the condensation of sodium silicate (also termed as waterglass). However, the reaction formed salts within the gel that needed to be removed by many long and laborious repetitive washings steps [64]. In following years, Teichner's group extended this approach to prepare optically transparent monoliths using tetraalkoxysilanes $\left(\mathrm{Si}(\mathrm{OR})_{4}\right)$ as the silica source [65]. The key of this process was to use an alcohol (e.g. methanol or ethanol), thus, the need for the tedious water to alcohol solvent exchange was eliminated [65-69]. This reduced the time required to make a final dried aerogel to approximately one day, which was a drastic reduction relatively to Kistler's original method. Presently, with the further developments of the sol-gel process, different alkoxysilane derivatives are used all together and with different solvents, which are needed for the homogenisation of the mixture and control of concentrations. Although, when switching from a protic to an aprotic (hydrocarbon) medium, alcohols are ideal intermediary solvents, as their bifunctional nature (polar/non-polar) promotes miscibility of water and the organic phase. But, surprisingly, the choice of the alcohol has a tremendous effect on pore structure and therefore also on final material properties [70-72]. The indication of different gelation solvents and related methodologies applied by different investigators, along with the different properties of the resulting aerogels, is reviewed by Soleimani et al. and Siouffi [47,73].

Due to the rapid development of sol-gel chemistry over the last few decades, the majority of silica aerogels are prepared today using silicon alkoxides as precursors [74-80]. The most common of the silicon alkoxides are the tetramethylorthosilicate (TMOS, $\left.\mathrm{Si}\left(\mathrm{OCH}_{3}\right)_{4}\right)$ and tetraethylorthosilicate (TEOS, $\mathrm{Si}\left(\mathrm{OCH}_{2} \mathrm{CH}_{3}\right)_{4}$ ) [42], with common chemical formula of $\mathrm{Si}(\mathrm{OR})_{4}$, that lead to the aerogels called "Silica". Many other alkoxides [81], containing various organic functional groups linked to silicon, can be used to give different properties to the gel. They have a general formula $\mathrm{R}_{X}^{\prime} \mathrm{Si}(\mathrm{OR})_{4-X}(1 \leq X \leq 3)$, being mono, di and trifunctional organo silanes, which lead to the aerogels named as "orgonosilsesquioxanes" [78]. Other common organo silica precursors with chemical formula of $(\mathrm{OR})_{3} \mathrm{SiR}^{\prime} \mathrm{Si}(\mathrm{OR})_{3}$ in which $\mathrm{R}^{\prime}$ is an alkyl, aryl or alkenyl bridge group between two elements of silica, lead to the "bridged organosilsesquioxane" products [19,35,82,83]. Alkoxidebased sol-gel synthesis avoids the formation of undesirable salt byproducts, and allows a much greater degree of control of the final 
products. The chemical equations for the synthesis of a silica gel from TEOS are as follows:

Hydrolysis

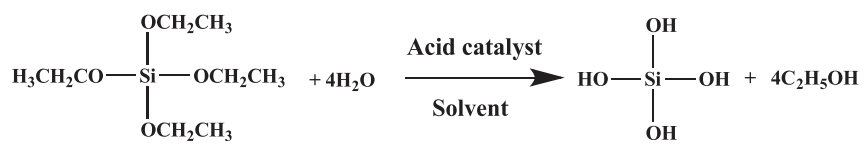

Condensation:
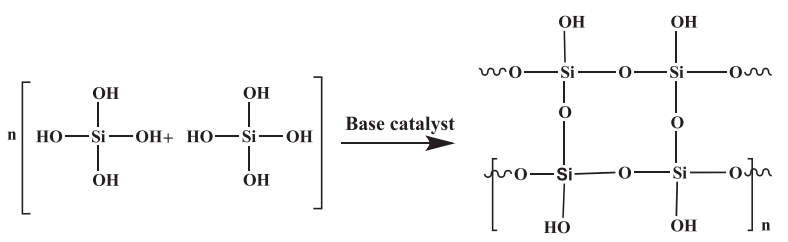

The above reactions are typically performed in methanol or ethanol $[66,67]$. The final density of the aerogel is dependent on the concentration of the silicon alkoxide monomers in the solvent.

The significant change from the liquid to the solid stage is termed the sol-gel transition. When a sol reaches the gel point, it is often assumed that the hydrolysis and condensation reactions of the silicon alkoxide reactant are complete. During this event, initially, the primary particles are formed, then they aggregate into secondary particles, and finally link together in a pearl necklace morphology [84]. The diagram presented in Fig. 1 shows the 3D network of porous silica, which is constructed by primary and secondary silica particles.

The kinetics of the sol-gel reactions is slow at room temperature and often requires several days to reach completion. For this reason, acid or base catalysts are added to the system [85,86]. The amount and type of the used catalysts play key roles in the microstructural, physical and optical properties of the final aerogel product. Acid catalysts can be any protic acid, such as $\mathrm{HCl}$ [18]. Basic catalysis usually uses ammonia, or ammonia buffered with ammonium fluoride [42].

Since the silica aerogels comprise highly open structures in which the secondary particles of silica are connected to each other with only few siloxane bonds, the structure of native aerogels is too fragile to be handled. One elegant but time consuming method to strengthen the solid skeleton of a silica gel is to enlarge the connection point between the secondary particles with more siloxane bonds via an "aging process" [87-89]. Common aging procedures for base catalyzed gels typically involve soaking the gel in an alcohol/water mixture of equal proportions to the original sol at a $\mathrm{pH}$ of 8-9 (ammonia) [90-92]. It has also been demonstrated that simply performing a thermal aging of the wet gel in water can be a key factor to decrease the gel microporosity before drying [42].

Generally, two different mechanisms might operate during aging that affect the structure and properties of a gel: (a) neck growth, from reprecipitation of silica dissolved from particle surface onto necks between secondary particles (Fig. 1(i)); and (b) dissolution of smaller particles and precipitation onto larger ones (Ostwald ripening mechanism) [89]. These two mechanisms will operate at different rates, but simultaneously, as illustrated in Fig. 1(ii). In addition, the particle clusters are brought in contact by Brownian motion and react with each other, increasing the number of siloxane bridges and reinforcing the silica network in neck regions [93]. The most effective and applied methods to overcome the weak mechanical properties of silica aerogels are reviewed in Section 4 of this manuscript.

\section{Drying techniques}

The final, and most critical, process in the synthesis of silica aerogels is the drying step. This is when the liquid within the gel is removed leaving only the linked silica network. Three main routes are commonly used for drying: (1) freeze-drying, in which the solvent inside of pores needs to cross the liquid-solid then the solid-gas equilibrium curve; (2) evaporation, which implies the crossing of the liquid-gas equilibrium curve of the solvent; (3) supercritical fluids drying (SFD), in which the supercritical condition is reached without crossing the equilibrium curve of the solvent [61].

Generally, in the freeze drying technique, the solvent in the pores is frozen and then sublimed under vacuum. The material obtained in this way is called a "cryogel". However, due to crystallization of the solvent within the pores, this process leads to cracked or even powder-like silica products with very large pores [42]. But this problem can be attenuated by using solvents with low expansion coefficient and high sublimation pressure, and also by using rapid freezing in liquid nitrogen at cooling rates over $10 \mathrm{Ks}^{-1}[94,95]$.

The capillary pressure, $P_{\mathrm{c}}(\mathrm{Pa})$, that develops during evaporative drying, causes the shrinkage of the gels. This pressure can be calculated by [42],

$$
P_{\mathrm{c}}=\frac{-\gamma_{1 v}}{\left(r_{\mathrm{p}}-\delta\right)}
$$
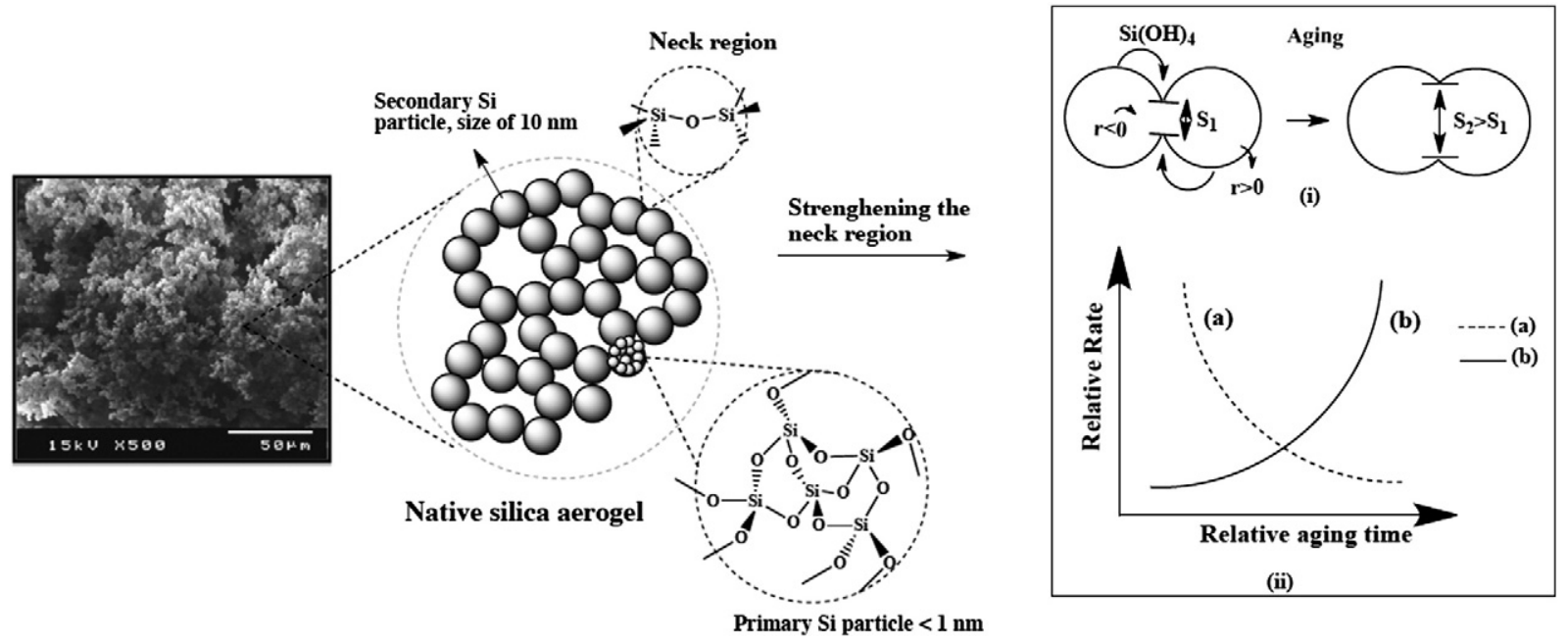

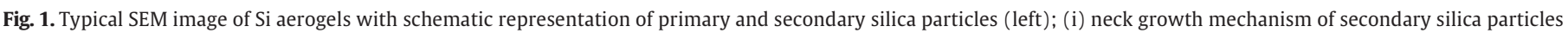
and (ii) relative aging rate as a function of time for two mechanisms (a, b) (right, adapted from [93] and [84]). 
$\gamma_{1 \nu}$ is the surface tension of the pore liquid $(\mathrm{N} / \mathrm{m}), r_{\mathrm{p}}$ is the pore radius $(\mathrm{m}) ; \delta$ is the thickness $(\mathrm{m})$ of a surface adsorbed layer.

Evaporation without specific surface treatments [96-99] usually results in "dense" (e.g., >0.25 g.cm ${ }^{-3}[98]$ ) and cracked materials, the so-called "xerogels". As explained by Phalippou et al. [100], the densification during evaporation comes from condensation of the remaining reactive silica species. When the silica wet gel is subjected to the capillary pressure, the initially far distance surface hydroxyl/alkoxy groups come close enough to each other to react and generate new siloxane bonds, leading to the irreversible shrinkage due to the inherent flexibility of silica chains. In addition, often the pore structures of xerogels collapse when compared to those of aerogels with the same composition [79,99,101-104]. Due to the different existing pore sizes within the gel, a high capillary pressure gradient develops inside the porous structure during the drying, which leads to mechanical damage. The capillary tension in evaporative drying may reach 100-200 MPa [47], and since the siloxane bonds within the aerogel monolith are not strong enough to withstand the capillary pressure then it results in shrinked and cracked xerogels [105].

One of the ways to overcome this problem is by strengthening the gel to stand the capillary stresses. This can be achieved by replacing some of siloxane $(\mathrm{Si}-\mathrm{O}-\mathrm{Si}$ ) bonds with flexible and non-hydrolysable organic bonds $(\mathrm{Si}-\mathrm{R})$, through the use of organosilanes as precursors to produce the aerogel network $[20,106,107]$. The organic group will allow the aerogel to spring back to its original wet gel size without resulting in any crack within the gel. Other methods involve changing the capillary force experienced by the network through surface modification of the silica with alkyl groups, and providing a surface with lack of $\mathrm{Si}-\mathrm{OH}$ groups [108]. Here, the general goal for the surface treatment is to produce a more hydrophobic surface by reacting the surface hydroxyl groups with hydrophobic reagents, such as $\left[\left(\mathrm{CH}_{3}\right)_{3}-\mathrm{Si}-\mathrm{OR}\right][109,110]$, or hexamethyldisilazane $[111,112]$. On the contrary to the surface rich $\mathrm{Si}-\mathrm{OH}$ gels, during the evaporation of the solvent in the hydrophobically surface treated gels, the alkyl groups repel one another originating the referred spring back of the aerogel $[70,106,113]$. The other methods to overcome the induced capillary pressures involve using low surface tension solvents [114], or adding additives to control the drying process [68]. Evaporation of a low surface tension solvent from the silica wet gel network reduces the capillary pressure when compared to the evaporation of an alcohol, since there is a direct relation between the surface tension and capillary pressure [115] according to Eq. (1).

In the supercritical fluid drying method, the liquid in the pores is removed above its critical temperature $\left(T_{\mathrm{cr}}\right)$ and pressure $\left(P_{\mathrm{cr}}\right)$, i.e. in supercritical state. In this condition, there are no liquid-vapor interfaces and, thus, no capillary pressure gradients arise. The supercritical fluid drying method can be performed: (1) with organic solvents in their supercritical state (generally with the synthesis alcohols and, consequently, near $260^{\circ} \mathrm{C}$ if ethanol or methanol is used), which is called HOT process [42]; or (2) by extracting the synthesis solvent with supercritical $\mathrm{CO}_{2}$ at a temperature slightly above the critical temperature of $\mathrm{CO}_{2}$ $\left(\sim 31^{\circ} \mathrm{C}\right)$, which is called COLD process. In the COLD process, the liquid part of the wet gels has to be exchanged with $\mathrm{CO}_{2}$, either in the liquid state [116], or directly in the supercritical state [117]. This process produces monolithic silica aerogels of rather large dimensions (for the typical cylindrical samples, the diameter is about $1-2 \mathrm{~cm}$ and length 5$6 \mathrm{~cm}$ ), but the dimensions of aerogel are obviously scaled by the sizes of the supercritical drying autoclave [28]. The lower temperature in the drying step and non-flammability of $\mathrm{CO}_{2}$ make the COLD process safer and cheaper than the HOT process. However, the development of the evaporative drying process to dry the silica wet gels by properly controlling the critical drying parameters $(T, P$, evaporation area and times) to achieve a xerogel material with final properties comparable with their aerogel counterpart, i.e. an aerogel-like material, would be a tremendous potential for scaling-up and cost reduction of such a material $[99,118,119]$. However, from an economical and large scale production point of view, there are also other items which can be significant in cost reduction of such materials [119]. Especially the cost of the starting silica precursors (normally, sodium silicate is cheaper than silicon alkoxides) and the several processing steps (e.g. the washing, the solvent exchange, and surface treatment) influence the global cost of the final aerogels or xerogels $[64,96]$.

Fig. 2 illustrates the complete aerogel synthesis process with its detailed steps, as explained before. Generally, the silica aerogels are made in two main steps: (1) the sol-gel process (the preparation of an alcogel) and (2) supercritical drying. Initially, the alcogel is prepared by promoting the hydrolysis and condensation reactions of silica precursors in the solution with solvent/water/catalysts, based on sol-gel chemistry. During this step, the primary silica particles will be created, and, then, during gelation, the primary particles coalesce and link to each other to form the secondary silica particles (see Fig. 1), resulting in a rigid three-dimensional network of silica. Then, the prepared silica wet gels can be subjected to different post-gelation treatments before drying, such as solvent exchange, washing and aging. In the drying step, the silica aerogel monolith can be obtained when the solvent inside the pores experience its supercritical condition and is released in this state without introducing any damage in the solid part.

\section{Mechanical reinforcement of silica aerogels}

Silica aerogels are cellular solids with a pearl-necklace-like skeletal network [84]. As indicated in Fig. 1, the weak points of such structure are the interparticle neck regions [120,121]. Although the native silica aerogels are sufficiently strong to be handled, their mechanical strength still is not adequate for them to endure and remain monolithic in some practical applications [54]. In fact, their intrinsic fragility that leads to low mechanical strength, imposes severe constrains on different potential load bearing applications of silica aerogels. Several techniques have been reported in the literature $[28,29]$ to reinforce silica aerogels' mechanical properties. The aim of such techniques is to develop aerogels of low density that can be easily deformed and show a capability to absorb shock energy during bending and compression $[14,30]$.

As stated before, the aging of wet gels leads to mechanically stronger inorganic networks [121,122], by increasing the strength of the final silica aerogels through dissolution and reprecipitation of silica at the surface of interparticle necks [123]. With this process, an improvement of approximately a factor of two in the modulus of elasticity will be achieved. But clearly, at the end, the reinforcement agent is still silica and remains a brittle material with low tensile strength.

Hybridization of silica aerogels $[34,124,125]$ can be an alternative solution for strengthening purposes, by promoting the co-gelation of the silicon alkoxide with hybrid precursors such as poly(dimethylsiloxane) (PDMS). Gels obtained in this way are termed "ORMOSIL" (ORganically MOdified SILica) hybrids. They have a more rubber-like flexibility. With 20 wt.\% PDMS, they can be elastically compressed to 30\% (by volume) with no damage [34].

Compounding of the inorganic network of aerogels with different polymeric systems has been performed by several chemical procedures. This method leads to a dramatic increase of tensile strength and robustness of the aerogels [26]. Moreover, incorporation of various fibrous supporting materials, such as polymeric fibers [55,57], carbon nanofibers [26], and fiberglass [126], into the aerogel systems, was also found to be quite effective in improving the mechanical properties of aerogels. Fiber matrix can support the aerogel and decrease the bulk size of aerogel within aerogel-fiber matrix composite [127]. So far, composites of fiber and silica aerogels have been produced with various methods in order to fortify the structure of silica aerogels.

The next sections of the present review paper will address all of above mentioned mechanical reinforcement strategies of the silica 


\section{Sol-Gel process}

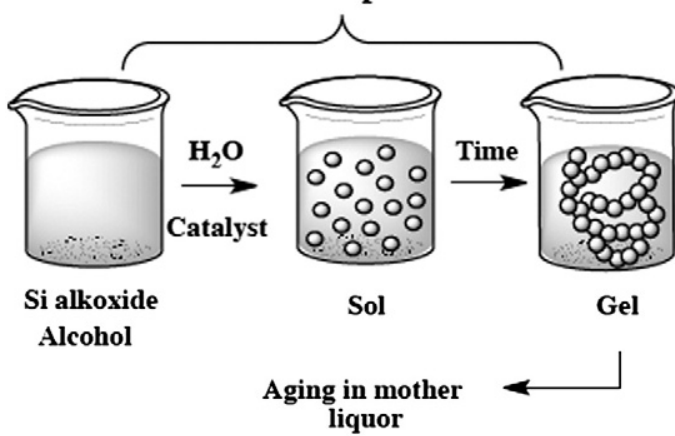

liquor

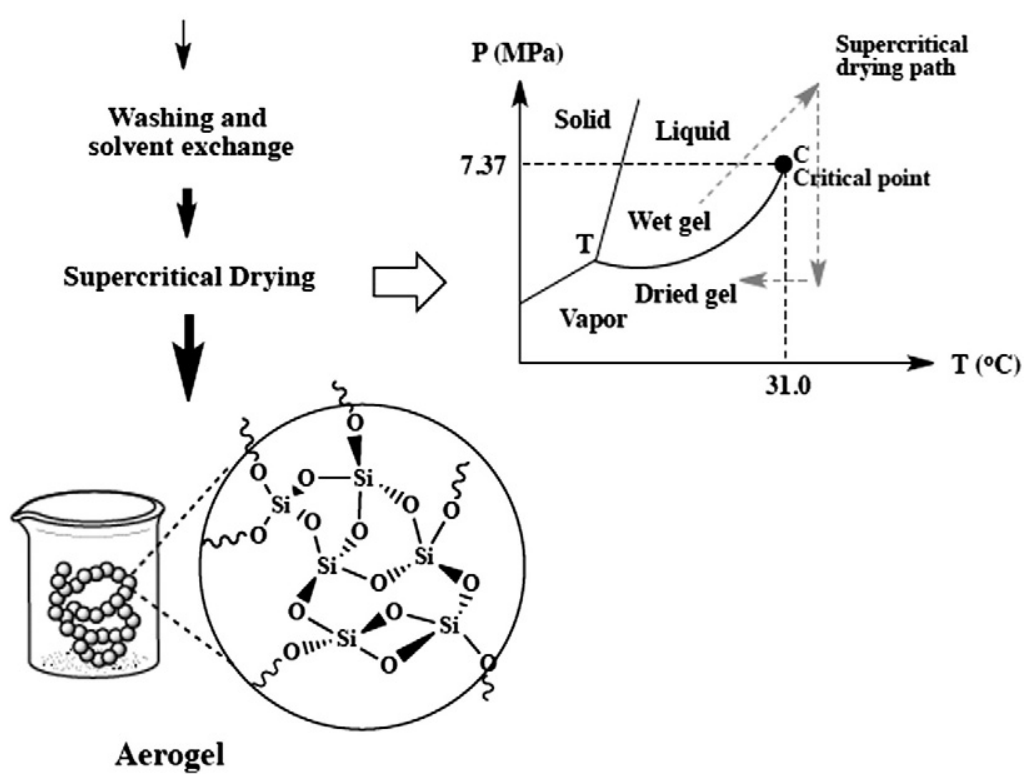

Fig. 2. Schematic representation of typical sol-gel synthesis procedure.

aerogels, and are a rather complete and updated literature survey on the subject.

\subsection{Structural reinforcement of silica aerogels}

Generally, the trifunctional organosilane compounds of the type $\mathrm{RSiX}_{3}$ (where, $\mathrm{R}=$ alkyl, aryl or vinyl groups, $\mathrm{X}=\mathrm{Cl}$ or alkoxy groups) produce flexible aerogels with reduced overall bonding and good hydrophobicity $[80,128]$, since one of the ends of Si atom contains a non-hydrolysable R group. Due to the presence of this organic group, $\mathrm{R}$, attached to the silica polymer chains, the inter-chain bonding is reduced resulting in an elastic and flexible three-dimensional matrix [19]. Kanamori et al. have shown that MTMS-derived gels can have reversible deformation upon compression [129]; Fig. 3 shows schematically the molecular structure of MTMS-derived silica aerogels. Rao et al. [19,107] studied the elasticity of these aerogels in terms of the Young's modulus

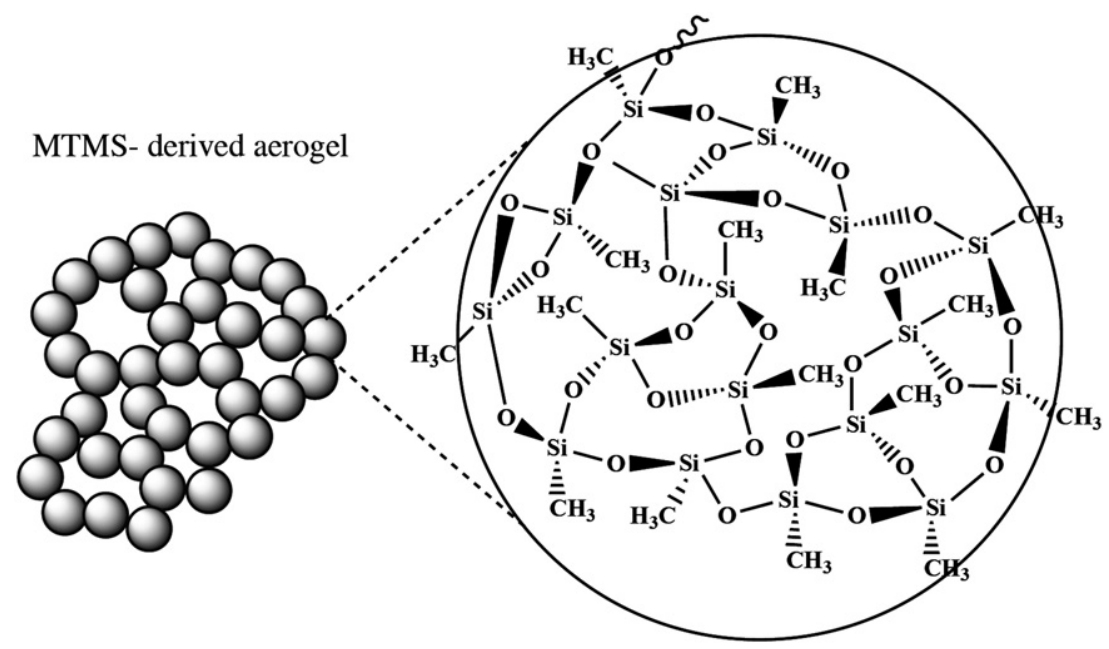

Fig. 3. Three dimensional network of MTMS-derived aerogels with its detailed molecular structure. 
$(\gamma)$, using uniaxial compression measurements. Aerogels with high elasticity, flexibility and with Young's modulus as low as $1.094 \times 10^{4} \mathrm{~N} . \mathrm{m}^{-2}$ could be obtained. They attributed the easiness of hydrolysis and condensation reactions to the length of methyl and methoxy groups within the silica precursor, as these are the smallest among all alkyl and alkoxy groups.

The MTES $\left(\mathrm{H}_{3} \mathrm{C}-\mathrm{Si}-\left(\mathrm{OC}_{2} \mathrm{H}_{5}\right)_{3}\right)$ precursor has also been used as a trifunctional organosilane compound to synthesize superhydrophobic and flexible aerogels $[20,130,131]$. In this case, each monomer of the MTES has one non-hydrolysable methyl group $\left(\mathrm{CH}_{3}\right)$, as in MTMS, and three hydrolysable ethoxy groups $\left(\mathrm{OC}_{2} \mathrm{H}_{5}\right)$. Therefore, only hydrolysable ethoxy groups are responsible for the matrix formation. As the condensation and hence the polymerization progresses, the number of hydrophobic $\mathrm{Si}-\mathrm{CH}_{3}$ groups increases compared to the number of hydrophilic $\mathrm{Si}-\mathrm{OH}$ groups, leading to an inorganic-organic hybrid silica network which is superhydrophobic and highly flexible and can recover or springs back after compression [20,107]. For the synthesis of such trifunctional organosilica based aerogels, Rao's research team [20] applied both the single-stage (base catalyzed) and two-stage (acid-base catalyzed) sol-gel processes. They have found that the two-stage process, due to step wise acid catalyzed hydrolysis and then base catalyzed condensation, leads to the built up of a systematic, complete and continuous network of silica, and thus, leads to highly flexible aerogels that can be compressed to as high as $\sim 60 \%$ by volume $[20,132]$. The singlestage process leads to less flexible aerogels $(<5 \%$ compression by volume), with non-continuous silica network, as a result of competitive hydrolysis and condensation occurring during the sol-gel process [20].

Apart from the synthesis methodology, the synthesis parameters, such as the rate of hydrolysis and condensation reactions, aging periods and dilution factor of silica precursors, have been found to have influence on the obtained mechanical and rheological properties of the trifunctionalized organosilica derived aerogels. For example, the effect of the precursor concentration on the elastic properties was examined, for the cases of MTMS and MTES, by varying the MeOH/MTMS and $\mathrm{MeOH} / \mathrm{MTES}$ molar ratios $(S)[19,20]$. The used molar ratios in the case of MTES-derived aerogels were $S=6.45,12.96$ and 19.35, and in the case of MTMS-derived aerogels were $S=21,28$ and 35. It was found that the density of the aerogel decreased with increasing $S$ ratios $[19,20]$, and the Young's modulus $(\gamma)$ of aerogels scaled with the bulk density in the same manner. For MeOH/MTMS ratios within the range from 14 to 35, the volume shrinkage and the density of the corresponding aerogels decreased from 28 to $7 \%$ and from 100 to $40 \mathrm{~kg} / \mathrm{m}^{3}$, respectively. The higher dilution of the MTES precursor $(\mathrm{MeOH} / \mathrm{MTES}=19.35)$ also resulted in the increase of the gelation time and in lower degree of polymerization of silanols and, thus, increased flexibility. The schematic image in Fig. 4(a, b) shows this molar ratio effect on the silica aerogel network. As it is clear, increasing the $S$ molar ratio (MeOH/MTES = 19.35), the distance between the reacting silica monomers and oligomers increases. Therefore, higher gelation time and less polymerization degree are observed. In addition, for higher dilution, the silica chains are quite separated from each other and large empty spaces or pores are formed in the aerogel network, leading to flexible aerogels. On the contrary, at lower dilution of the MTES precursor $(\mathrm{MeOH} /$ MTES = 6.45), due to the less separation distance between the silica monomers and oligomer chains in the sol, the reacting species can react easily, leading to extensive polymerization in three dimensions, which results in dense and rigid polysilsesquioxane structures [19,20]. Fig. 5(a, b) shows the change in length versus the applied load for both MTMS and MTES-derived aerogels synthesized with different dilutions of the silica precursor. As shown in this figure and based on the above arguments, both types of aerogels, for higher dilution, show higher changes in their lengths when compared with the aerogels that were prepared with lower dilution (in the same applied loads). This observation proves the claim that higher dilution of organosilane precursors results in aerogel with lower Young's modulus and, therefore, higher flexibility. Fig. $6(\mathrm{a}-\mathrm{c})$ shows the maximum bending possibility for MTES-derived aerogels with different dilutions of the silica precursor. The above arguments can be further confirmed by these photographies. As it can be seen, the lowest dilution of organosilane leads to less flexibility; on the contrary, the aerogels with the highest $S$ ratio show the highest flexibility. Further bending of these samples resulted in crack formation within the structure. Because of this new property, i.e. flexibility, the aerogel can be bent to any shape and acts as a good shock absorber as well [20].

The elastic limit of the prepared flexible MTES-derived aerogel could be determined via a uniaxial compression test by applying different loads. Fig. 7 shows the mechanical behavior of the MTESderived aerogel with $\mathrm{MeOH} / \mathrm{MTES}$ molar ratio $(S)$ of 19.35 . As shown in this figure, the decrease in the length of the aerogel is almost linear with the applied load (path from point $O$ to point $A$ ). At point $A$, there is a sudden decrease in the compression, indicating no further compression. Within the area under the curve, the aerogel resists the deforming forces by bringing into play internal restoring forces and recovers its original length when the deforming forces are withdrawn [20].

Durães et al. $[79,80,99]$ also studied the effect of the $S$ molar ratio and drying parameters on resulted properties of silica aerogels/xerogels with the samples containing 100\% MTMS, 100\% ETMS and for the aerogels/xerogels with 25\% ETMS and 75\% MTMS. It was concluded that higher molar ratios of silica precursor/solvent $(S)$ resulted in less extension of the cross-linking and, consequently, lower density of the materials and higher flexibility. It was also found that with increasing the size of R group from methyl (MTMS) to ethyl (ETMS) group, more linear structures of secondary silica particles would be created due to the increase of steric hindrance in the medium and the consequent decrease of the condensation rate [80].

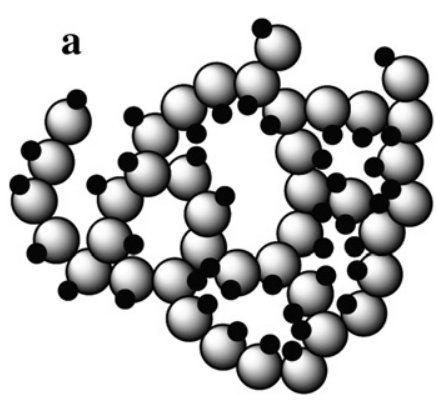

Less polymerization: Flexible structure

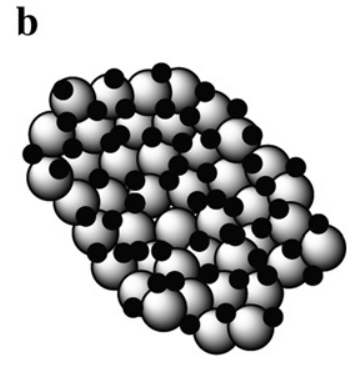

Extensive polymerization: Rigid structure 

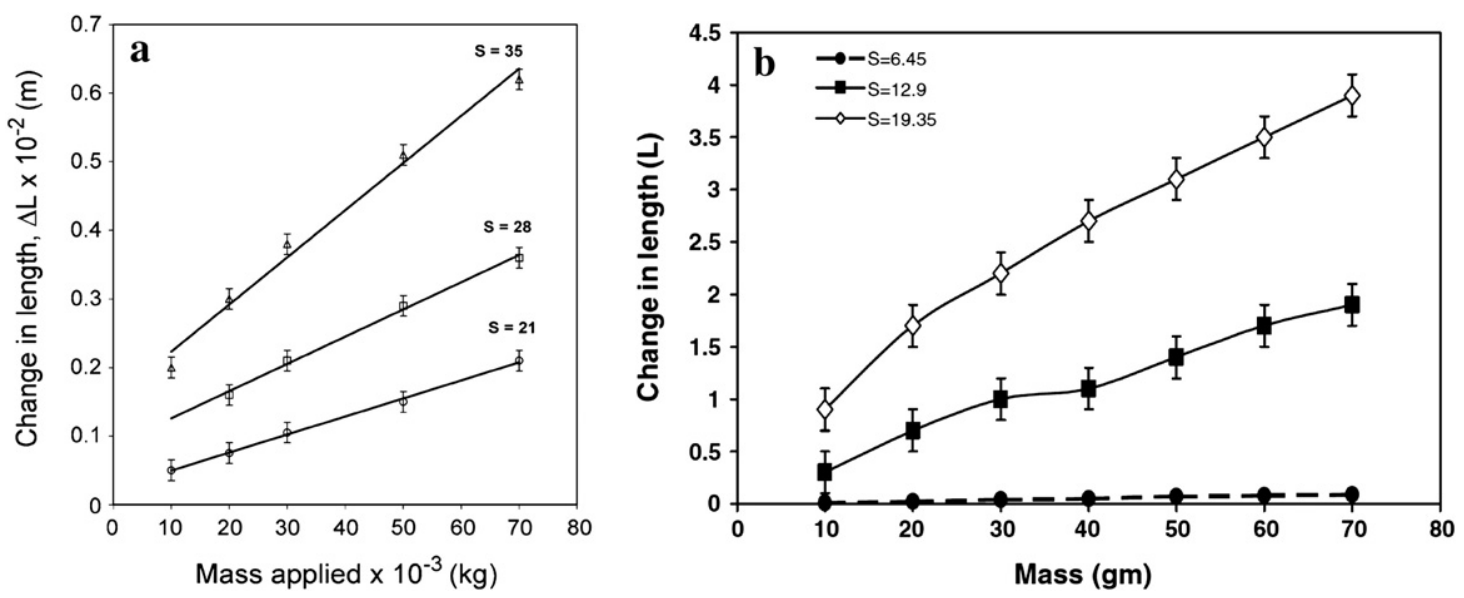

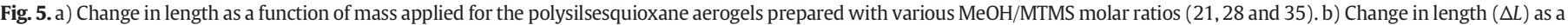

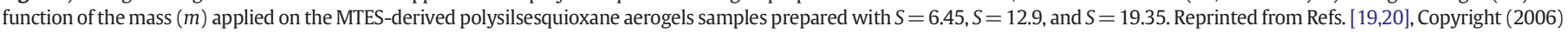
(2009), with permission from Elsevier.

A limited selection of the monofunctional and difunctional organosilane compounds of the type $\mathrm{RSiX}_{3}, \mathrm{R}_{2} \mathrm{SiX}_{2}$ as well as $\mathrm{X}_{3} \mathrm{Si}-\mathrm{R}$ $\mathrm{SiX}_{3}$ bis silane precursors, in which $\mathrm{R}$ is an alkyl or aryl group, is provided in Fig. 8 [83,133-136]. In this figure, different organosilica precursors are separated under different categories and, from them; various aerogels with different material properties can be prepared. Some of these silica precursors contain special organic functionalities that care useful for surface decoration or surface treatment of the aerogel for application of one's needs. To a certain extent, the inorganic-organic (hybrid) materials (ORMOSIL) that can be obtained from these precursors combine the most important properties of their constituents, like high transparency (glasslike), low processing temperatures (polymer-like), sufficient thermal stability (silicone-like), and are easily prepared because of a unique availability of the respective precursors.

Besides the simple metal or silicon alkoxide precursors (for example, TMOS) that, after hydrolysis and condensation (see sol-gel reaction mechanism at Section 2), lead to the formation of an inorganic oxidic network with only siloxane ( $\mathrm{Si}-\mathrm{O}-\mathrm{Si}$ ) bonds, the organo (alkoxy)silanes, depending on what type of functionalities they have, can be used to incorporate polymerizable organic substituents, such as epoxy, vinyl, or methacryloxy groups, into the final aerogel product [29]. The $\mathrm{Si}-\mathrm{C}$ bonds in such molecules are stable under the mild conditions of sol-gel processing [137].

In addition to hybrid organo (alkoxy) silane precursors, the crosslinking of the silica backbone with more flexible and elastic alkyl bridged bis-silane precursors can improve the strength of the aerogels systematically. For example, as reported by Meador et al. [21], a non- cross-linked aerogel made from a combination of TMOS and BTSPD showed complete recovery after $25 \%$ compression, with an approximate modulus of $4 \mathrm{MPa}$ and densities of $0.2 \mathrm{~g} . \mathrm{cm}^{-3}$. A high concentration of the disulphide in the formulation yielded lower density monoliths, which recovered completely from as much as $75 \%$ compression, as shown in Fig. 9(a). The inset of Fig. 9(b) shows the same sample before, during and after compression with finger pressure. This sample recovered $98 \%$ of its original length during the first ten minutes after compression and, after thirty minutes, the recovery was $99.6 \%$.

Similar results have been reported by Meador et al. [49,138], for aerogels synthesized by replacing up to $40 \%$ of TEOS or TMOS in the silica backbone with the alkyl linked BTMSH. As can be seen from Fig. 10, the BTMSH reduces stiffness in the silica backbone by replacing some of the more rigid $\mathrm{Si}-\mathrm{O}-\mathrm{Si}$ bonds with flexible hexyl links. The resulting aerogels presented a modulus up to $23 \mathrm{MPa}$ and almost complete recovery from a state of $25 \%$ compressive strain. The evidence of increasing mechanical performance using hybrid organic-inorganic bridged alkoxysilanes is consistent with the work of Loy, Shea and co-workers $[35,83,139]$, which have examined a wide range of precursors to synthesize bridged silsesquioxanes. Typically, bridge bis-silane precursors allow the pore size control that is directly related to the nature and length of the bridge. Best results for controlling the porosity were obtained using a stiffer structure such as an arylene chain. More flexible bridges such as alkyl chains lead to more compliant aerogels but tended to shrink more, reducing porosity.

More recently, Randall et al. [29] examined the relative merit of three types of bis-silane precursors with different lengths of the alkyl
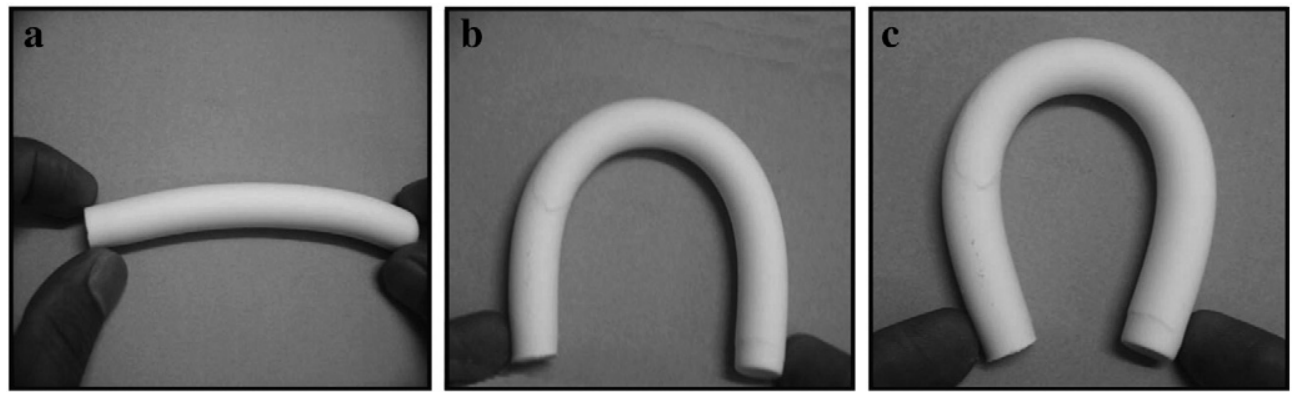

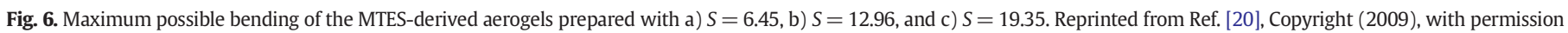
from Elsevier. 


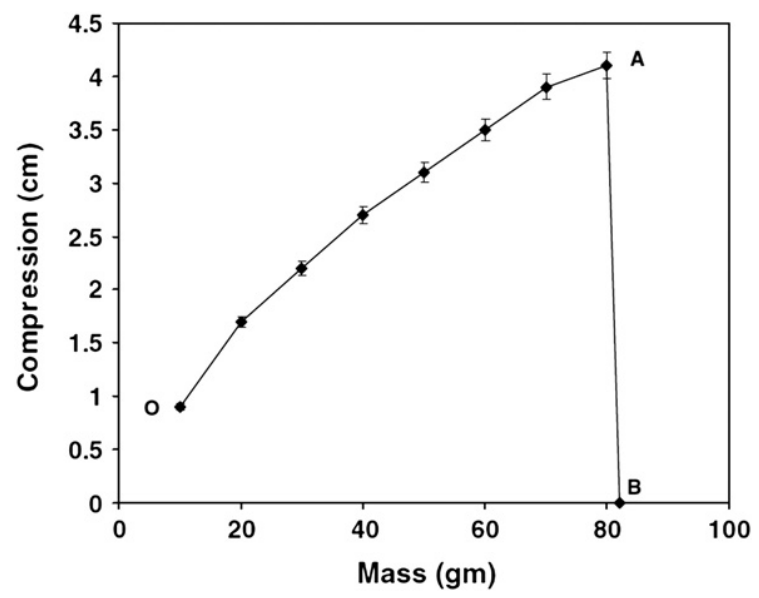

Fig. 7. Compression of an MTES-derived aerogel sample as function of the applied compression load. Reprinted from Ref. [20], Copyright (2009), with permission from Elsevier.

groups on epoxy reinforced silica aerogels. As shown in Fig. 11, this research team applied four types of bridged alkyl linked bis-silanes and a difunctional silica precursor to which the extended chemical structures are shown in Fig. 8. In the case of co-gelation of bridged bis-silane precursors with TEOS, the flexible alkyl links/bridges between the secondary silica particles, depending on the size of the bridge, can confer flexibility to the network. All of these precursors improved the elastic recovery of the aerogels with an amount as small as $15 \%$ included in silica backbone. Randall et al. also reduced the number of $\mathrm{Si}-\mathrm{O}-\mathrm{Si}$ bonds by using a difunctional silane, DMDES, in order to improve the elastic response by reducing the stiffness of the silica network. However, additional incorporation of bis-silane precursors (up to $45 \%$ of any bissilane) reduces the compressive modulus. Authors indicated that the hexyl linked bis-silane (BTMSH) is the most effective among the bissilanes as compared with others in their work. Only BTMSH produced aerogels with high mass yields, indicating complete hydrolysis and condensation under the reaction conditions they studied.

Nearly similar results have been reported by Vivod et al. [140], in which the incorporation of the hexane linked precursor (BTMSH) in the silica backbone was found to enhance the flexibility and the strength of the aerogels. The wet gel could be bent easily without any fracturing and this can improve the manufacturability of BTMSH-derived aerogels. This sample also displayed great recovery at higher Si concentrations after compression to $25 \%$ strain.

\subsection{Polymer reinforced silica aerogels}

It has been proved that compounding of silica backbone with polymer is an effective way to increase mechanical strength by as much as three orders of magnitude while only doubling the density over those of native or non-reinforced aerogels [32,119]. Compounding the silica network with polymer can be achieved by different type of interfacial interaction of secondary silica particles (inorganic parts) with appropriate functionality on the organic polymers. Depending on the chemical relationship between the polymer and the surrounding silica network, polymer/sol-gel composites are placed into two categories: Class I hybrid composite aerogels and Class II hybrid composite aerogels [141-143].

\subsubsection{Class I hybrid composite aerogels}

The composites that are formed as a result of weak interactions, like van der Waals forces, electrostatic forces, or hydrogen bonding, between the organic and inorganic phases are in the category of this class of hybrid materials [144,145]. In this type of composite materials, organic molecules, pre polymers or even polymers are embedded in the inorganic matrix being totally independent from each other. These materials are synthesized by carrying out a number of different routes, e.g. the formation of the inorganic network through hydrolysis and condensation of the silica precursors, in the presence of the organic compound or by polymerizing organic monomers in the porous inorganic host. The most prominent examples representing class I are organic dyes or biomolecules incorporated in porous sol-gel matrixes $[146,147]$. The guest molecules are physically dissolved together with the precursors of the inorganic host (e.g., TEOS or TMOS) or introduced to the sol state, and become entrapped in the gel that results from condensation and drying of the mixture.

Other examples of this group of hybrids are provided by composites formed upon incorporation of different polymers, such as poly(ethylene oxide) [148,149], derivatives of nylon 6 [150] and poly(ethyl acrylate) [151], into $\mathrm{SiO}_{2}$ matrices synthesized by the sol-gel method. Here, in the composites whose organic components have polar groups, the formation of hydrogen bonds between the components of the system [152] is important to understand the nature of the synthesized materials. The hydroxyl groups in the repeating units of the polymer, like ethylene glycol oligomers [149] or poly(vinyl alcohol) [153,154], are expected to produce strong secondary interactions with the residual silanol groups generated from acid-catalyzed hydrolysis and polycondensations of $\mathrm{SiO}_{2}$ matrix.

Although the resulted hybrid gels possess proper transparency and thermal stability without any phase separation between the two components, there is no particular example from this family of composite with the purpose of mechanical reinforcing of native silica aerogels. Indeed, this class of hybrid materials is traditionally used to improve the very poor mechanical properties of organic polymers such as polysiloxanes polymer (PDMS) with incorporation of an inorganic filler of $\mathrm{SiO}_{2}$ $[155,156]$.

Since post-gelation washing is often required in the processing of the silica aerogels, class I hybrid silica composite aerogels are rarely studied. This is due to the existence of weak interfacial bonds between the two phases, and consequent easy leaching of the polymer from the pores of silica by the extensive solvent exchange, either during the post-gelation washing steps or solvent passing through the gel pores during the supercritical drying $[144,145]$.

Instead, this class of polymer composite aerogels seems to be straightforward to make mainly xerogel composites through the introduction of the monomer inside of the initial sol or by polymerizing of the appropriate monomer in the post-gelation steps. The composites obtained from this method show a decrease in the elastic modulus with substantial increase (3 times) in their ultimate compressive strength [144].

From a practical point of view, the ambient dried aerogel-like class I composites are advantageous, since they are cost effective and easy to produce. Moreover, the elimination of the post-gelation processing steps is an asset for further mass production of this type of materials [157].

\subsubsection{Class II hybrid composite aerogels}

Class II hybrid aerogel composites are referred to the composite network in which the interfacial bonding between the organic phase and silica is based on strong covalent bonds. This type of hybrid aerogels was studied by Mackenzie et al. [158] who considered the different rearrangement of covalent bonding between the two phases.

Generally, this approach requires molecular precursors that contain a hydrolytically stable chemical bond between the element that will form the inorganic network during the sol-gel processing and the organic moieties. Since, in these materials, the polymer connects points along the skeletal framework of 3D assemblies of nanoparticles, the resulting composites are referred to as polymer cross-linked aerogels. These materials possess the advantages of both organic and inorganic materials and are expected to present unique properties that are different from the individual organic or inorganic materials. 


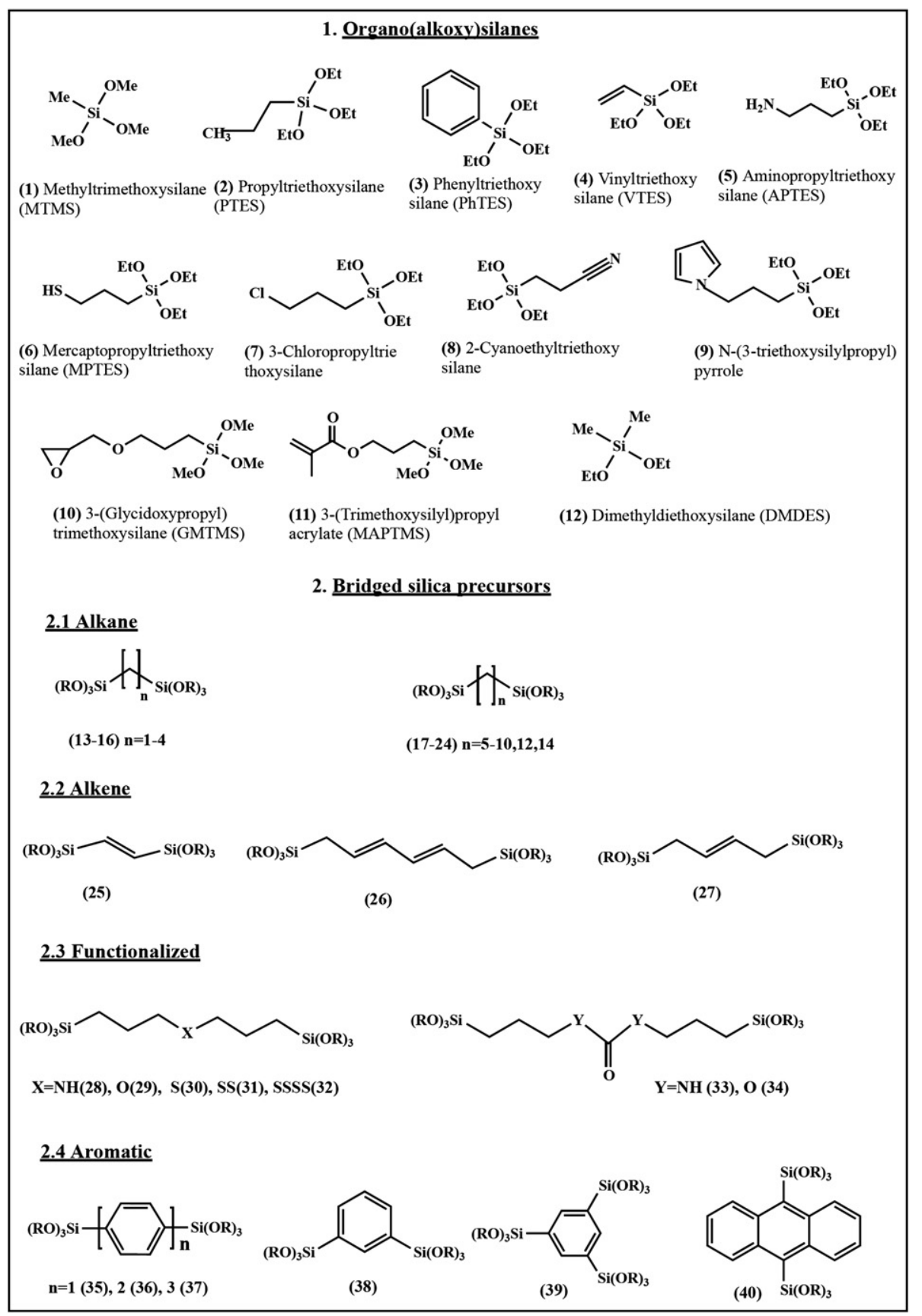

Fig. 8. Organo(alkoxy) and bridged silanes used as precursors for sol-gel-derived (hybrid) materials.

Until now, several polymeric systems such as polyurea, polyurethane, poly (methyl methacrylate), polyacrylonitrile and polystyrene have been used to reinforce silica aerogels [22-24,26,159]. In fact, the underlying inorganic framework plays the role of structure-directing agent (template). The improvement of mechanical properties is attributed to reinforcement of interparticle necks, which are the weak points of the aerogel skeletal network (Fig. 1). In turn, the stabilization provided by the cross-linking polymer is attributed to the extra chemical bonds created by interparticle polymeric tethers.

Extending polymer cross-linked aerogel composition to additional polymers, optimization processes for desired material properties and simple manufacturing are currently the focus of attention of several research groups such as Leventis et al. [26,119], and the group led by Meador [29,32] in the NASA Glenn Research Center.

4.2.2.1. Liquid and vapor phase polymer cross-linking. Native silica aerogels can be reinforced with different organic polymers, starting from the functionalization of secondary silica particle surfaces with appropriate functional groups. The functionalization of the surface of silica particles within the inorganic network can be achieved through cocondensation of the core precursors, namely TMOS or TEOS, with silica precursors containing the special organic functionality in their chemical structures. Then, the polymerization normally can be performed by introducing the organic monomer through the post-gelation solvent 
a

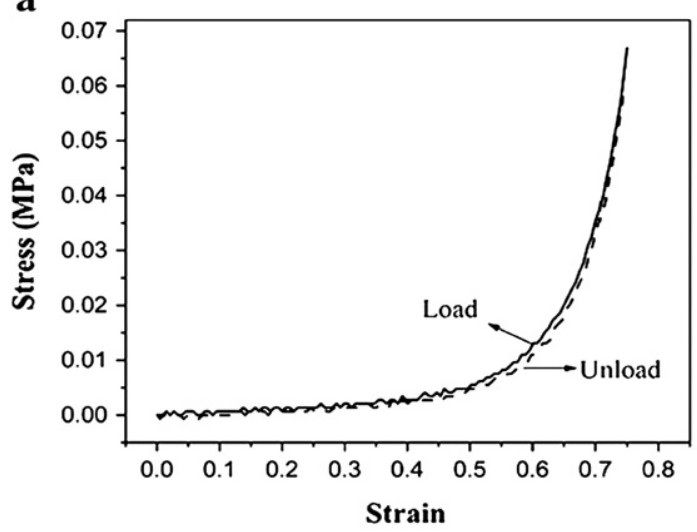

b

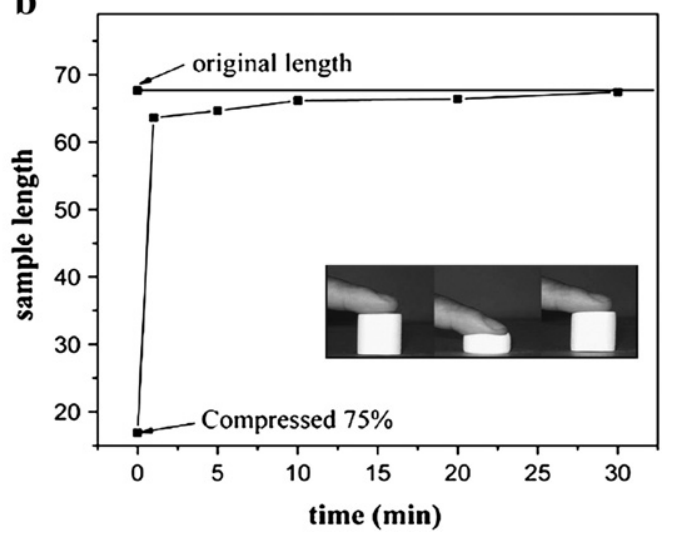

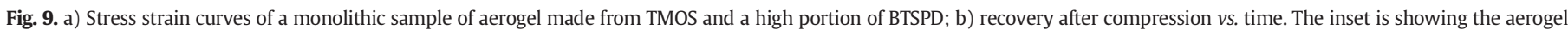
sample compressed by finger pressure and demonstrating full recovery. Reprinted from Ref. [21], with permission from the Royal Society of Chemistry (RSC).

exchange and then promoting the reaction of the silica functionality with monomers (Fig. 12). This multistep liquid-phase based reinforcing approach is quite long due to the solvent exchange process, the slow diffusion rates of monomers in the wet gel and the heating necessary to promote the reaction of the monomers with the silica surface, which is followed by more solvent exchanges and supercritical drying $[23,28,29,48,52,53,84,160-162]$. In addition, the monomer is usually introduced in the wet gel by soaking the gel inside of the monomer solution and, thus, sometimes the monomer does not uniformly diffuse in the gels and, during the replication process, deviations of the aerogel properties are detected [49]. In order to eliminate these time consuming and tedious post-gelation steps, two effective alternatives to the previous approach can be used. The first alternative is to introduce the organic monomers in the initial sol, which contains the whole silica precursors and gelation solvent, in order to carry out the procedure in a simple one pot fashion $[22,49,163]$. This method provides the in situ formation of inorganic silica network with organic monomer contained in the pores. As in this step the monomers are already present inside the inorganic matrix of the wet gels, the diffusion of the monomer to the gel is not a limiting factor, therefore, the polymerization reaction is more

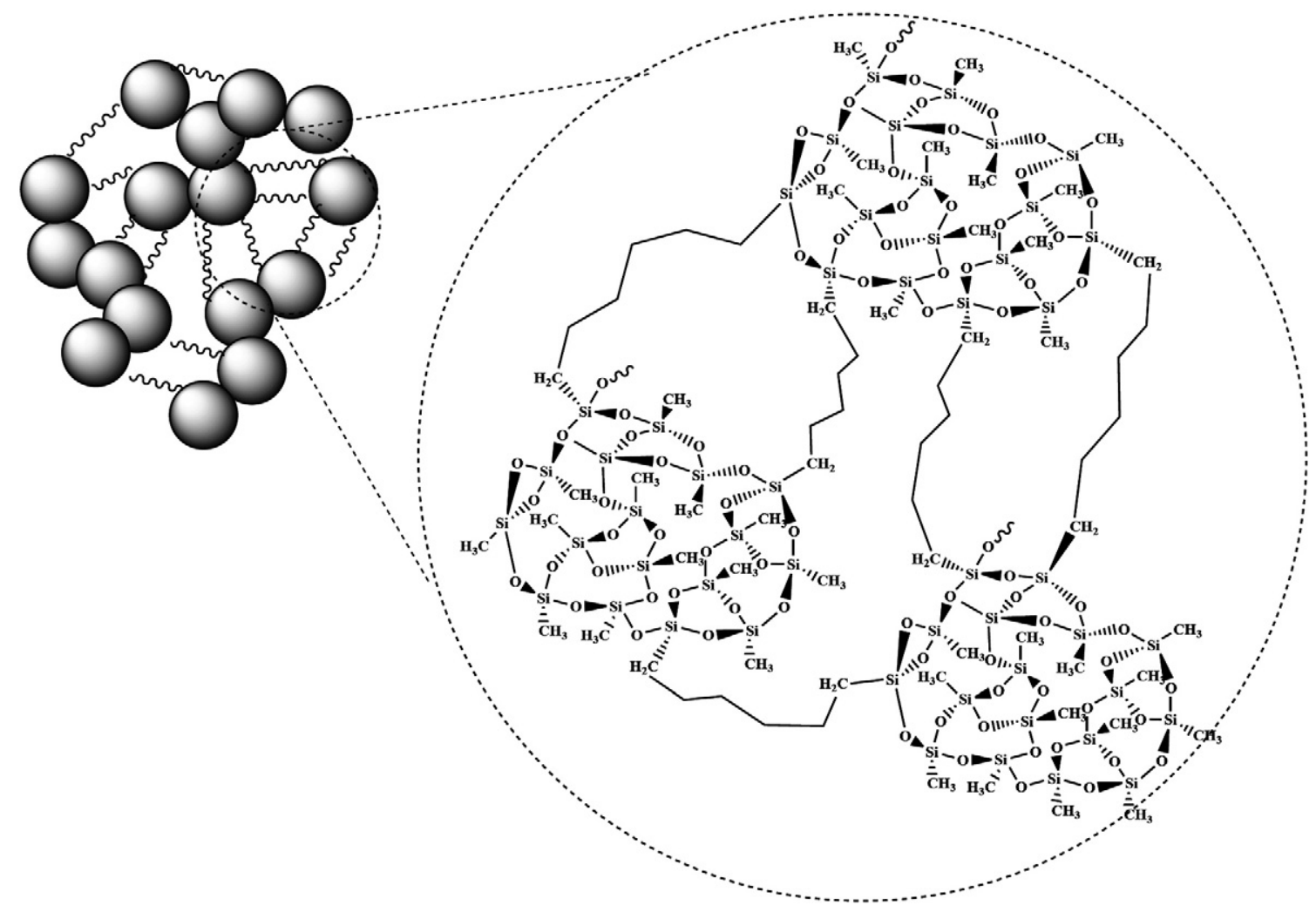

Fig. 10. Three dimensional network of MTMS/BTMSH-derived silica aerogels with its detailed molecular structure. 


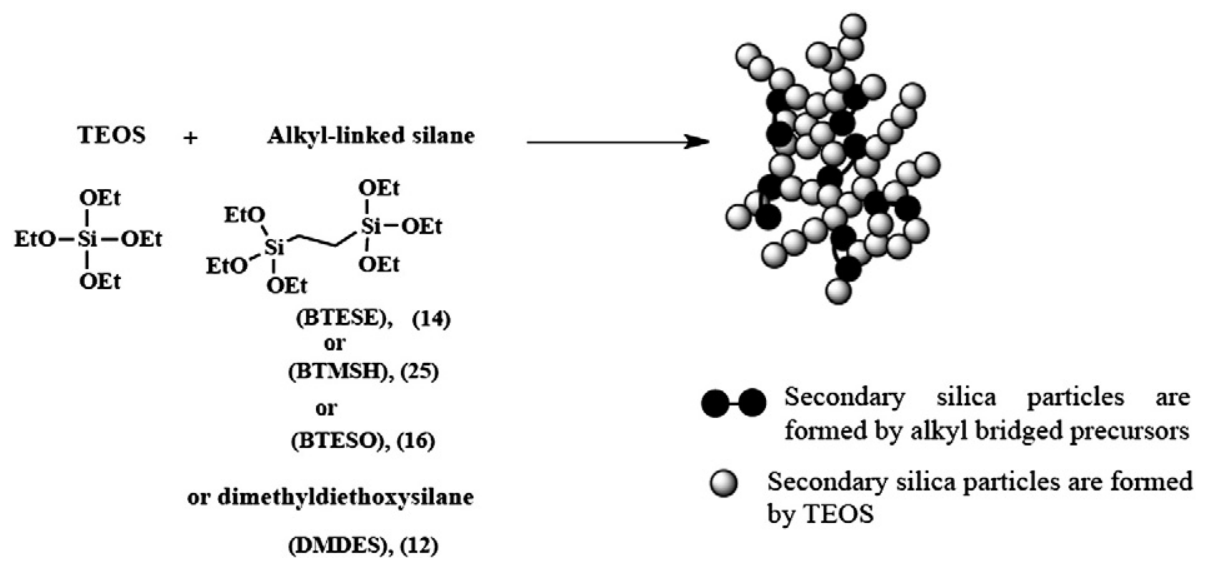

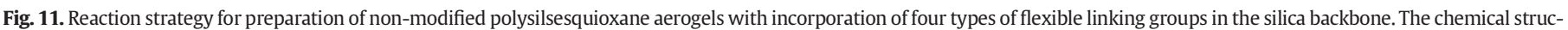
tures of the alkyl linked bis-silane precursors are indicated in Fig. 8 with their related numbers.

efficient. Moreover, the elimination of time consuming steps of soaking the wet gel inside the monomer solution, in the in situ process, makes it more cost effective [54]. Fig. 13 presents precisely the difference between the two liquid based routes for the development of polymer reinforced silica aerogels. The other recent approach for eliminating the post-gelation treatment is to cross-link the aerogels through gas phase after they have been supercritically dried $[25,164]$. This can be carried out through the deposition of a desired monomer throughout the pores' surface of an aerogel, by means of chemical vapor deposition (CVD) or atomic layer deposition (ALD) [25,164-166].

Overall, all liquid-phase cross-linking strategies, whether one pot or multi step, cause significant increase in strength (up to $8 \mathrm{MPa}$ ) but, on the other hand, they increase the density $\left(\approx 0.5-0.8 \mathrm{~g} . \mathrm{cm}^{-3}\right)$ and decrease the surface area $\left(\approx 40-600 \mathrm{~m}^{2} \cdot \mathrm{g}^{-1}\right)$. The density and then mechanical properties can be well controlled by varying several factors, such as silicon molar concentration in the sol $[21,23,29,48,49,138,167]$ the organic monomer concentration $[23,48,49,51,138,163]$, the gelation solvents $[138,167]$ and so on. The best samples with optimum physical and mechanical properties were selected by some authors through a statistical DoE studies [29,32].

For the CVD procedures, the density of the silica aerogel composites was in the range $0.095-0.230$ g. $\mathrm{cm}^{-3}$, and it also could be controlled by variation of the exposure times of the functionalized silica aerogel in the monomer vapor [25]. In this approach, the typical cross-linked aerogels can be 31 times stronger than the original silica aerogels before CVD treatment, with only two-fold reduction in the surface area.

Different possible polymer reinforcements of silica aerogels, with their detailed chemical approaches, are extensively studied and reviewed within different research groups. Table 1 summarizes some examples of polymeric systems that have been applied to improve the mechanical properties of silica aerogels by cross-linking. Some of the physical and mechanical properties of the obtained materials are also presented.

4.2.2.2. Advanced methods for polymer reinforcing of silica aerogels. As outlined in the previous section, the one pot, in situ, cross-linking process of silica is efficient for large scale production of these materials and can eliminate the time consuming of post-gelation treatments of the wet gels. But, performing the cross-linking part with hydrolysis and condensation of silica precursors is not always responsive to some kind of polymerization techniques. In fact, gelation of silica is based on acidic and basic catalyzed ionic processes, and to perform the crosslinking reaction simultaneously it is necessary to have a polymerization system with higher activation barrier than gelation, or performing through non-ionic process like free radical polymerization [119]. The implementation of this procedure for free radical polymerization seems to be effective but still needs further post-gelation thermal or light treatment.

The free radical polymerization can be achieved through modification of silica surface with olefins. From there, the polymerization follows the "grafting to" or radical coupling process, in which the coupling of the radicals to the surface of silica aerogels occurs [52]. It can be also performed via surface decoration of silica with radical initiator, followed by polymerization through the "grafting from" approach, initiating the polymerization from the surface of silica aerogels $[161,168]$. With the modification of the silica surface with Si-AIBN radical initiator (Fig. 14), Leventis et al. [161] applied the "surface initiated grafting from" approach for integration of polymethylmethacrylate (PMMA), polydivinylbenzene (PDVB) and polystyrene (PS) in the silica network, with polymerization starting from the surface of the silica aerogel. The radicals were used to initiate the polymerization of vinyl groups grafted to the surface of the silica gel. Although this approach is significantly simpler and allows highest control on polymer coating around silica, and mechanical properties comparable with the "grafting to" approach, the polymerization still is uncontrolled, which increases the polydispersity of the polymer. On the other hand, if a significant portion of the initiator remains in the silica matrix, it causes the decomposition of the azo bridged silsesquioxane during the heating of the gels, and this leads to a weakening of the mechanical properties.

In order to overcome the problem arising from free radical surface initiated reaction, and to allow a greater control on molecular weight of the polymer and, indirectly, on the mechanical properties of the silica aerogels, Boday et al. [24] applied a controlled polymerization reaction for cross-linking the surface of silica with PMMA. For this purpose, they implemented the "'Atom Transfer Radical Polymerization"' (ATRP) technique [169], for controlling the molecular weight and polydispersity of the polymer on silica aerogel surfaces. In their approach, initially, the sol-gel processable ATRP initiator was synthesized. Afterwards, as shown in Fig. 15, the surface of silica was modified with the ATRP precursor through co-gelation with TMOS precursor. Then, in next step, the vinyl polymer grew from colloidal secondary particles of silica via the ATRP process and, after supercritical drying; the polymer covers the surface of the silica network and reinforced it. This approach allows the incorporation of well-defined polymers with a versatile methodology for polymerization with controlled amount of vinyl groups and cross-linkable monomers. The resulted polymer reinforced 


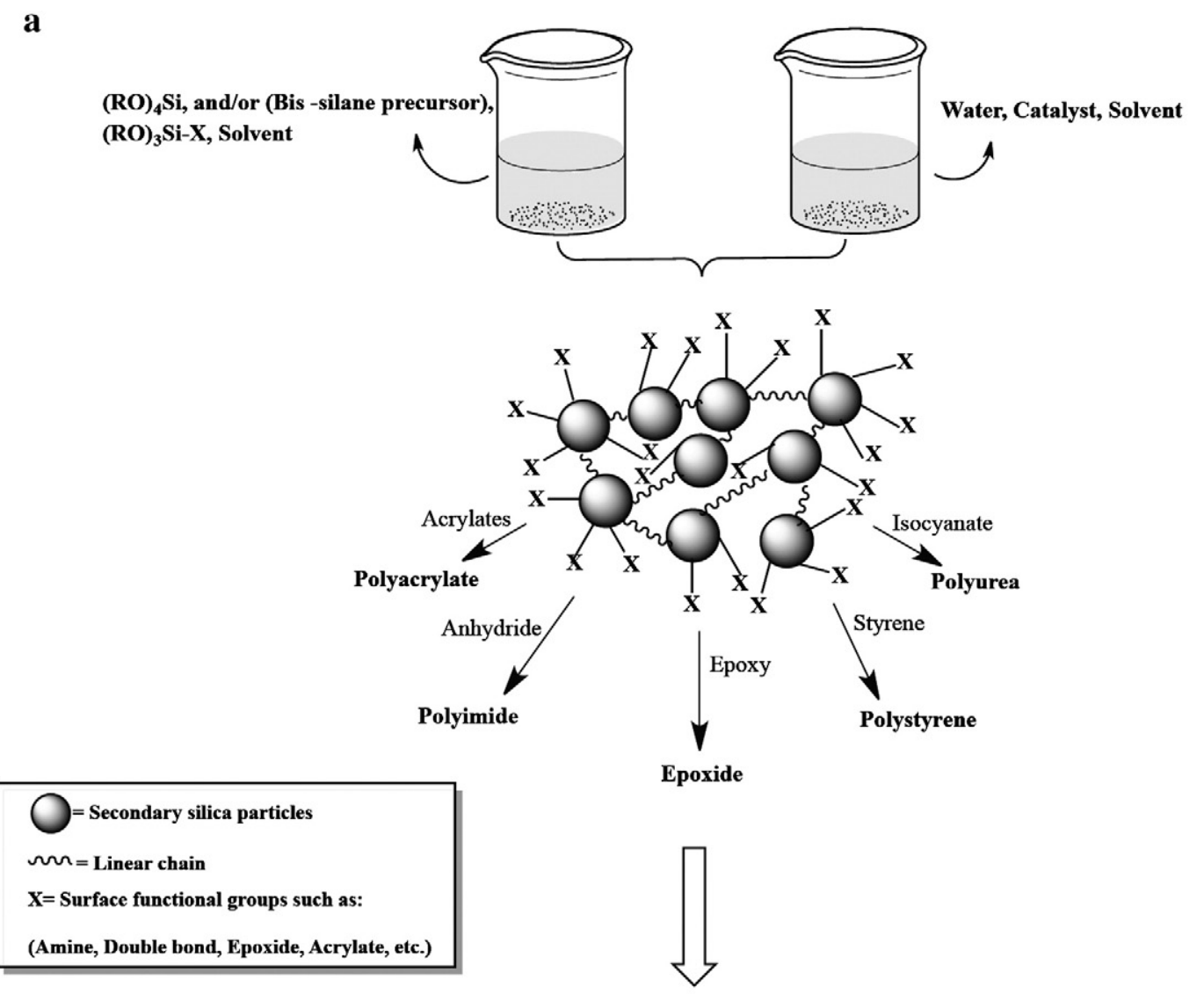

b

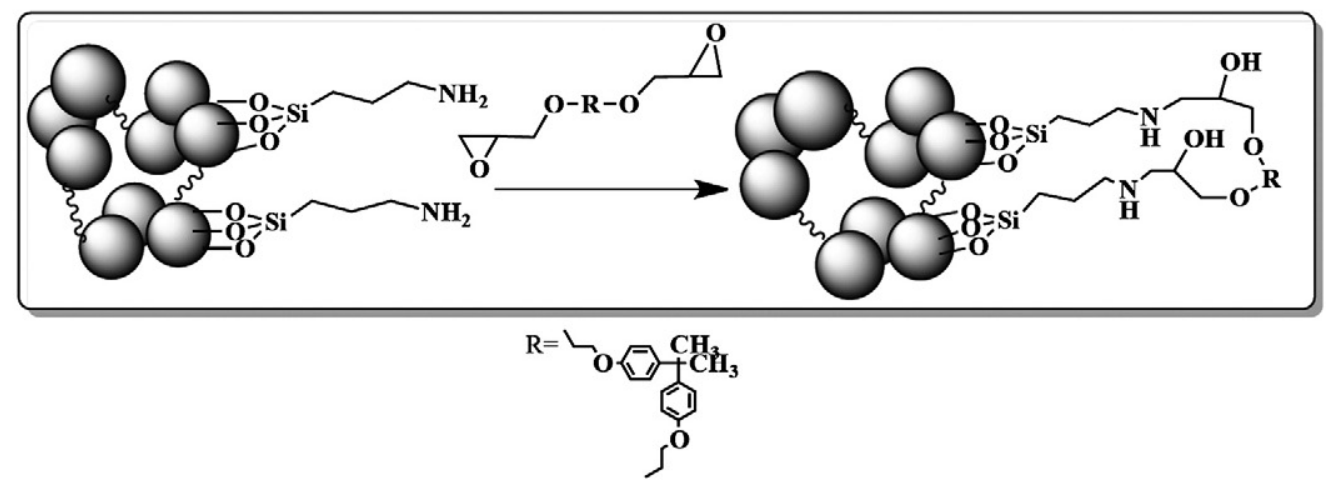

Fig. 12. a) Concept of polymer reinforcement using reactive groups on the silica surface; b) Epoxy cross-linking of silica aerogels. Inspired in [49].

aerogels comprised polymers with polydispersities from 1.2 to 1.8 . The aerogel bulk densities were in the range of $0.177-0.47 \mathrm{~g} . \mathrm{cm}^{-3}$, and flexural strength ranges from 15.4 to $63.5 \mathrm{kPa}$, with surface areas in the interval $144-681 \mathrm{~m}^{2} \cdot \mathrm{g}^{-1}$.

For the production of aerogels with approximately the same physical properties and mechanical strength by different reinforcing strategies, Table A.1 was built (see the Appendix A) to give a global comparative idea about the cost efficiency to produce a typical cylindrical strong aerogel with $12 \mathrm{~cm}$ length, $1 \mathrm{~cm}$ of diameter and bulk density of $\approx 0.3 \mathrm{~g} . \mathrm{cm}^{-3}$. In this table, several issues such as consumption of starting material, amount of solvent, drying conditions and resources (representing mainly the energy needs) and time of preparation (representing the human resources) are compared for different strategies considered in Section 4.2.

\subsection{Fiber reinforced silica aerogels}

One of the interesting methods for strengthening the silica aerogels is to use fibers as a second phase. Incorporation of any commercially available or laboratory developed fibrous supporting materials, such as carbon nanofibers, fiberglass, insulation fibers, alumina tiles, dacron, cotton wool and polymeric nanofiber, into the aerogel systems, is quite effective in increasing the mechanical properties of aerogels. So far, composites of fibers and silica aerogels have been produced by various methods in order to fortify the structure of silica aerogels and to overcome the network poor mechanical properties. The fiber matrix will support the aerogel and decrease the bulk size of aerogel within the aerogel-fiber matrix composite. By introducing a sol into a fibrous batting network, allowing it to gel and performing drying by supercritical 
a

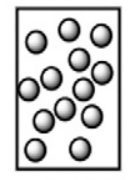

Si precursors/ Solvent/ $\mathrm{H}_{2} \mathrm{O}$

Sol

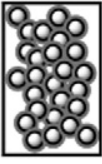

Heating (up to $72 \mathrm{hrs}$ )

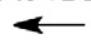

$1 \mathrm{wash} /$ day $* 4$ to remove excess polymer

\section{Cross linked}

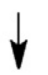

b

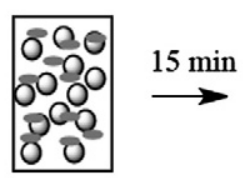

Sol

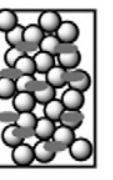

Gel
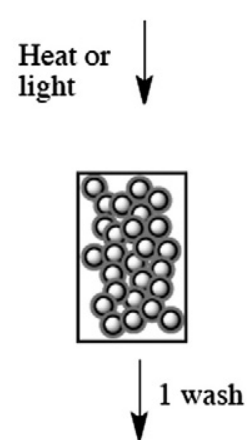

Supercritical drying
Soak in monomer bath (24hrs)

(1)

Gel

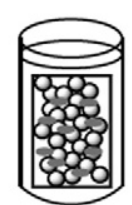

$\downarrow$
1 wash/day $* 4$

to remove water

Supercritical drying

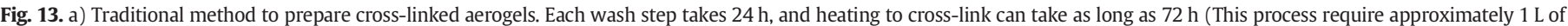

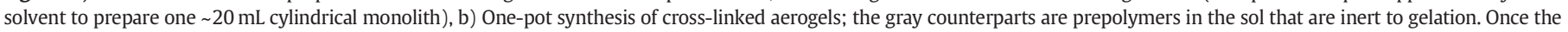
gel is formed, it can react to initiate cross-linking. After one wash, which removes any unreacted components, the monolith is supercritically dried.

Table 1

Examples of polymeric systems, with the method of cross-linking to silica aerogels and selected properties of cross-linked aerogels.

\begin{tabular}{|c|c|c|c|c|c|c|}
\hline Silica & Method of cross-linking & Cross-linking polymer & Density $\left(\mathrm{g} \cdot \mathrm{cm}^{-3}\right)$ & $\begin{array}{l}\text { Ultimate strength } \\
(\mathrm{MPa})\end{array}$ & Surface area $\left(\mathrm{m}^{2} \cdot \mathrm{g}^{-1}\right)$ & Reference \\
\hline \multirow{2}{*}{$\begin{array}{l}\text { Non-modified } \\
\text { Silica (Si-OH) }\end{array}$} & Post-gelation washing & Polyurea & $0.241-0.564$ & $0.01-4$ & $140-541$ & {$[28,84]$} \\
\hline & Gas phase & Polycyanoacrylate & 0.235 & $-{ }^{a}$ & 200 & {$[164]$} \\
\hline \multirow{8}{*}{$\mathrm{NH}_{2}$-modified } & \multirow{5}{*}{ Post-gelation washing } & \multirow{3}{*}{ Polyurea } & 0.48 & $186 \pm 22$ & 261 & {$[160]$} \\
\hline & & & $0.06-0.523$ & $26.62-261.26$ & $8.3-320$ & {$[23]$} \\
\hline & & & $0.3-0.954$ & $0.25-1.24$ & $-{ }^{d}$ & {$[162]$} \\
\hline & & Polystyrene & $0.413-0.768$ & $0.059-0.251$ & $180-393$ & {$[53]$} \\
\hline & & Epoxide & $0.21-0.59$ & $0.04-1.9$ & $267-856$ & {$[29,48]$} \\
\hline & \multirow{2}{*}{ One pot synthesis } & Epoxide & $0.198-0.842$ & $1.5-2.7$ & $36-392$ & [49] \\
\hline & & Polyimide & $\sim 0.1$ & Up to 2.5 & $240-260$ & {$[163]$} \\
\hline & Gas phase & Poly(cyanoacrylate) & $0.095-0.23$ & $0.021-0.651^{b}$ & $522.7-964.2$ & {$[24]$} \\
\hline VTMS-modified & Post-gelation washing & Polystyrene & $0.122-0.332$ & $0.6^{\mathrm{c}}$ & $8-750$ & {$[52]$} \\
\hline \multirow{4}{*}{ AIBN-modified } & \multirow{3}{*}{$\begin{array}{l}\text { Post-gelation washing \& } \\
\text { one pot synthesis }\end{array}$} & Polystyrene & $0.2-0.549$ & $0.09-28.86$ & $65.98-668.3$ & \multirow{3}{*}[161]{} \\
\hline & & $\begin{array}{l}\text { Polymethyl } \\
\text { methacrylate }\end{array}$ & $0.198-0.807$ & 93.13 & $46.05-781$ & \\
\hline & & Polydivinylbenzene & $0.27-0.31$ & 0.85 & $247-731$ & \\
\hline & One pot synthesis & Polyacrylonitrile & $0.177-0.475$ & $-{ }^{\mathrm{d}}$ & $144-681$ & {$[22]$} \\
\hline
\end{tabular}

The rupture strength increased $(32 \times)$ to $17.6 \mathrm{~N}$.

${ }^{\mathrm{b}}$ Three-point bend-beam flexural strength.

${ }^{c}$ Only in $25 \%$ strain.

${ }^{\mathrm{d}}$ Not reported. 


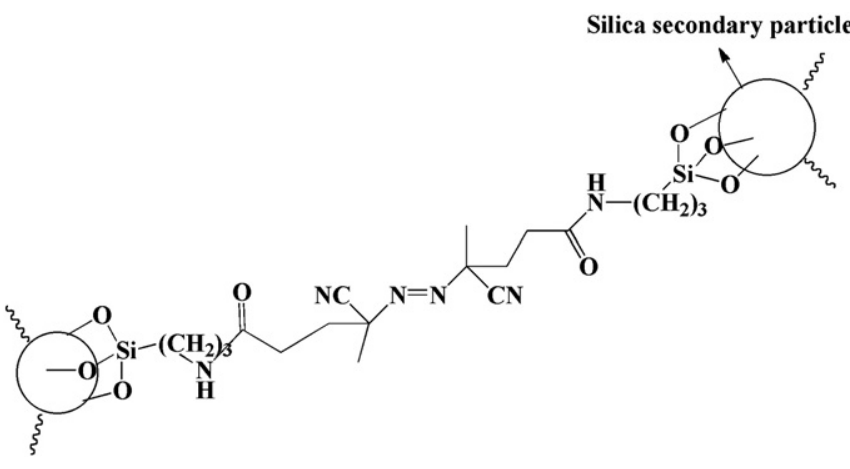

Fig. 14. Chemical structure of silica wet gels obtained from a bis-triethoxysilane derivative of AIBN. Inspired in [161].

fluids extraction, fiber-aerogel composites can be produced. Fig. 16 shows the general process for fiber reinforcement of silica aerogels with a typical scanning electron microscopy (SEM) micrograph of the final silica aerogel-fiber composites.

Aerogel blankets have been produced with improved thermal and mechanical performances by scientists at Aspen Aerogels Inc. [170]. This type of aerogel composite was made by pouring the silica precursor solution on top of a fiber batting blanket, previously placed in a casting container, and allowing gelation to occur within a few minutes after the addition of a catalyst.

Zhang et al. have incorporated non-woven polypropylene fibers into silica aerogels by immersing them into a silica sol [57]. The surface of the resulting wet gel composites was modified with TMCS and hexamethyldisiloxane, in order to make it hydrophobic. This surface modified composite gel was dried at ambient pressure and $200^{\circ} \mathrm{C}$ to produce a hydrophobic aerogel-like silica-fiber composite. In this procedure, the authors claimed that fibers acted as a supporting skeleton that could increase the mechanical properties of the silica aerogels, although no mechanical characterization was reported for these aerogel composites.

Li et al. [55] developed a flexible thin film of aerogel, reinforced with incorporation of electrospun polyurethane (PU) and containing poly(dimethylsiloxane) (PDMS) in the initial sol. In their procedures, by controlling the kinetic of the sol-gel reaction, the polymer nanofibers (previously developed by electrospinning) were immersed inside of a low viscosity sol before the gelation process. In this method, the fragility of the developed thin film aerogel composites was reduced by strengthening the mesoporous structure in three dimensions in different scales: i) macroscopically, through electrospun fibers; ii) microscopically, by thickening the interconnecting interparticle necks within the mesoporous silica with a silanol terminated poly(dimethylsiloxane) (PDMS) oligomer. With this procedure, bendable aerogels with high surface area $\left(604-759 \mathrm{~m}^{2} \cdot \mathrm{g}^{-1}\right)$, large pore volume and maximum flexural strength of $200 \mathrm{kPa}$ were developed.

Karout et al. [58] studied biocatalysts based on carbon and ceramic fiber composite-silica aerogels and examined the influence of fiber reinforcement on biocatalytic activity of these aerogels for lipase encapsulation. The synthesized aerogels were very elastic, and could easily recover after five tests without significant loss of mechanical integrity. Paramenter et al. [171] have reinforced silica aerogels with 5 to $25 \mathrm{wt} . \%$ of ceramic fibers of silica, alumina and aluminoborosilicate with different diameter and length. During supercritical drying, a high proportion of fibers supports the matrix, reduces the shrinkage of silica aerogels and results in a lower matrix density. In this method, the hardness and compressive strength did not show any regular trends with fiber percentage for a given matrix density. However, the elastic moduli increased with an increase in fiber percentage for a given matrix density [171].

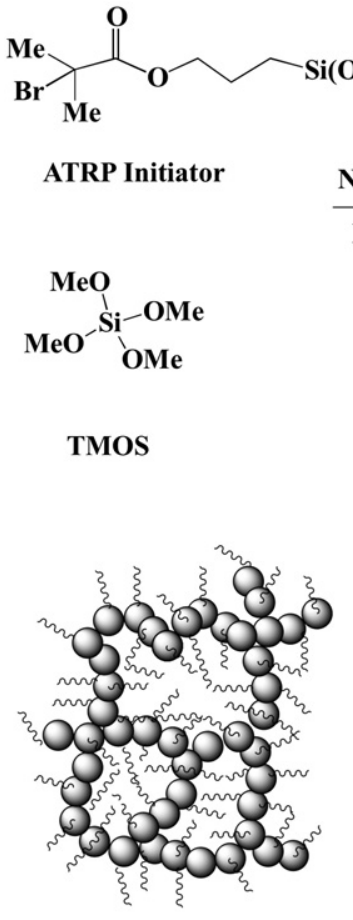

PMMA-gel
$\mathrm{Si}(\mathrm{OEt})_{3}$
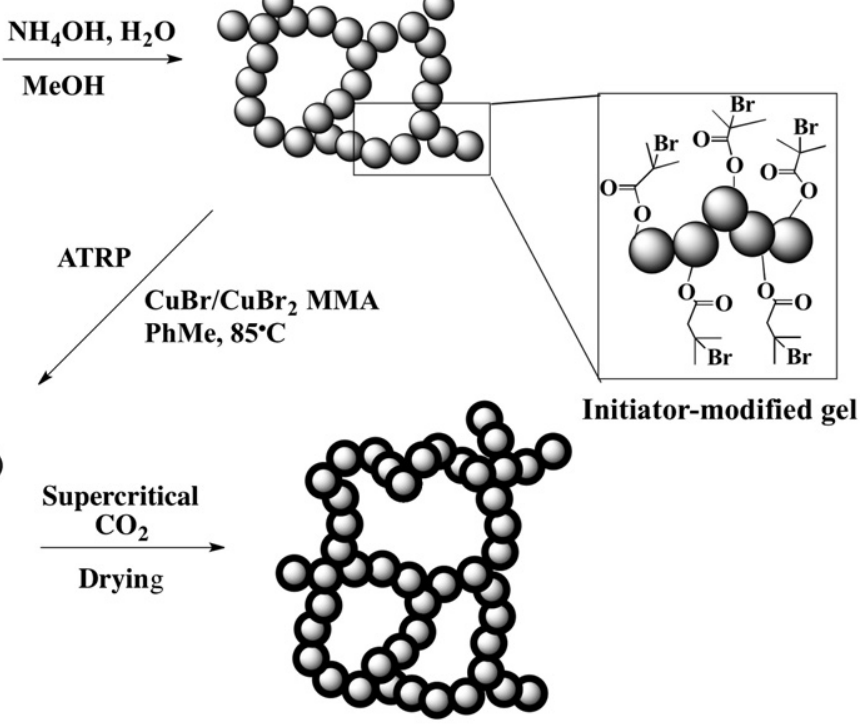

PMMA-silica aerogel

Fig. 15. Formation of an initiator-modified gel, ATRP growth of PMMA on surface and supercritical drying to afford a silica-PMMA composite aerogel. Adapted from Ref. [24]. 


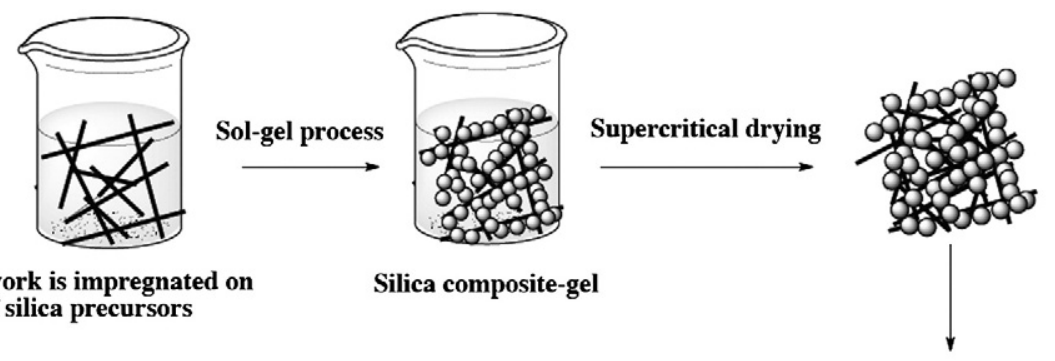

Fiber network is impregnated solution of silica precursors

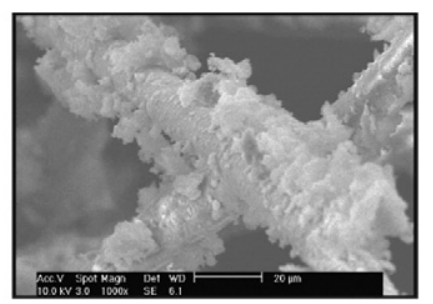

Fig. 16. General procedure for preparation of the fiber-silica composite aerogel. The SEM photo is related to a hydrophobic silica aerogel reinforced with polypropylene nonwoven fibers, which was prepared by Zhang et al. Reprinted from Ref. [57], by permission of the publisher (Taylor \& Francis Ltd, http://www.tandf.co.uk/journals).

Recently, Yuan et al. [126] reported the synthesis of silica aerogelfiber glass composites, using a press forming method. They studied the effects of the addition of glass fiber and $\mathrm{TiO}_{2}$ as a second phase and the forming pressure on improving the heat insulation and the mechanical properties of the silica aerogel composites. It has been proved that by addition of the glass fibers, the strength of the composites was improved but the heat insulation property was destroyed. They have shown that for an increase of the forming pressure from 0.5 MPa to 2.0 MPa, the compressive strength of the composites increased from $0.3 \mathrm{MPa}$ to $1.2 \mathrm{MPa}$ and the apparent density increased from $0.35 \mathrm{~g} . \mathrm{cm}^{-3}$ to $0.53 \mathrm{~g} . \mathrm{cm}^{-3}$. Authors claimed that with an increase of the forming pressure, the precursor was pressed tightly and the fibers interweaved with each other, and strengthened the aerogels.

Insoluble polysaccharides, such as cellulose and biologically based fibers, are other candidates for reinforcing of inorganic silica aerogels [172,173]. Cai et al. [174] synthesized a high durable and flexible cellulose-silica nanocomposite aerogel with in situ synthesis of silica in cellulose gels. In their report, firstly the native cellulose was prepared as a hydrogel with cellulose II crystallinity through dissolution and coagulation. The resulting gels displayed significant mechanical strength, light transmittance and open structure. Then, the nanoporous gel structure of cellulose, with interconnected nanofibrillar network, was impregnated with TEOS (in $\mathrm{MeOH} / \mathrm{H}_{2} \mathrm{O}$ ). The silica loading was more than 60 wt.\%. After synthesizing of the silica gel by sol-gel, the final composite gel was dried with supercritical $\mathrm{CO}_{2}$ and resulted in the cellulose-silica aerogel composites. Fig. 17 shows the typical mechanical strength of this flexible cellulose-silica composite aerogel [174]. The compression modulus of this composite is more than two orders of magnitude higher than that of a silica aerogel, and about 50 times higher than that of the aerogel prepared from bacterial cellulose [175]. In this method of reinforcement, in contrast to the increased density from $0.14 \mathrm{~g} . \mathrm{cm}^{-3}$ for native silica aerogels to about $0.6 \mathrm{~g} . \mathrm{cm}^{-3}$ for composite aerogel, the thermal conductivity of the composites, which was determined by the steady-heat-flow method, increased only from approximately $0.025 \mathrm{~W} \mathrm{~m}^{-1} \mathrm{~K}^{-1}$ to $0.045 \mathrm{~W} \mathrm{~m}^{-1} \mathrm{~K}^{-1}$. The synthesized cellulose-silica composite can be useful as thermal insulator material with high mechanical strength and stability, together with the ability to form sheets, fibers, or beads.

Meador et al. [27] studied the use of the carbon nanofibers as reinforcement agents for polymer cross-linked aerogels. They examined the effect of incorporation of $5 \mathrm{wt} . \%$ carbon nanofibers in di-isocyanate cross-linked silica aerogels. Using statistical design of experiment, they examined the effect of the addition of carbon nanofibers on mechanical and other properties of the resulting aerogels. According to $\mathbf{a}$

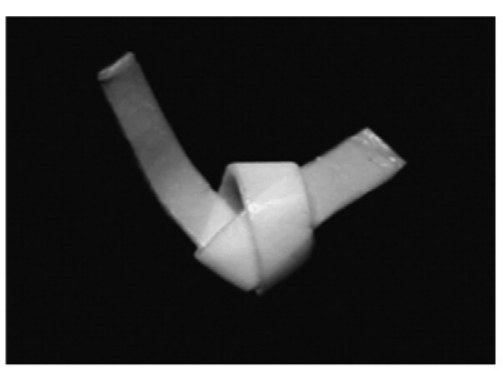

b

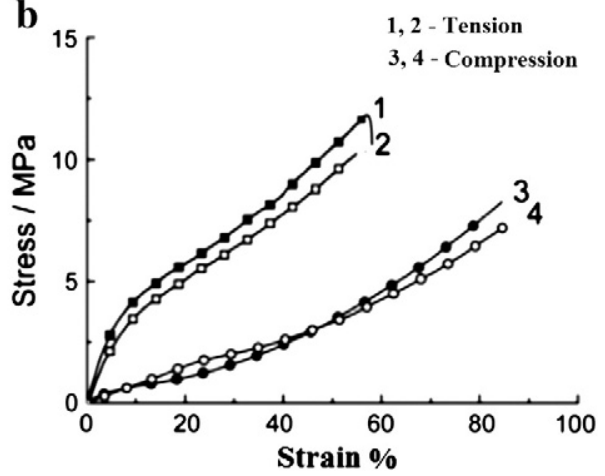

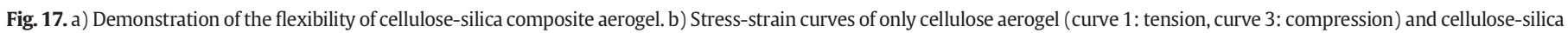
composite aerogel (curve 2: tension, curve 4: compression). Reprinted from Ref. [174], by permission of the publisher (John Willy and Sons). 
their established model, it is possible to obtain a three-fold increase in compressive modulus without any increase in density of the monoliths by increasing the fiber concentration up to $5 \%$. And also, a five-fold increase of tensile stress at break was obtained by incorporation of $5 \%$ fiber, at lowest concentration values of total silane and cross-linker agents. The density or porosity was not influenced with the addition of the fibers, while the surface area was slightly reduced with increasing of fiber concentration. Therefore, the incorporation of carbon nanofibers provides a way to significantly improve the mechanical properties of aerogels with densities bellow what can be achieved by cross-linking with polymers. This is important for increasing the mechanical integrity when a specific application requires high strength monoliths with high porosity and low densities. As the author claimed, the biggest impact of carbon nanofiber reinforced aerogels may be an improvement of strength of hydrogels before polymer cross-linking, which results in no breakage of fiber contacting wet gel during the initial demolding process. So, this may allow the manufacturing of low-density polymer reinforced aerogel at large scale.

Overall, in terms of fiber reinforcing of silica aerogels, it is necessary to consider the chemical compatibility of both phases in terms of hydrophobicity and hydrophilicity [59]. In most cases, introducing chemical covalent bonds between the fiber and silica network versus forming only weakly physical bonds, may lead to long-term network integrity and stability. Apart from the chemistry, different fiber matrices can require different processing conditions, which, in turn, originate different reinforcement results. For instance, the methodology of reinforcing of silica aerogels with fiber blankets seems to be more straightforward and effective when compared to the reinforcement of aerogels with separate and non-woven fibers [176]. In terms of non-woven fiber application, the process is more tedious and complicated when compared to a fiber blanket. That is due to the need of avoiding the sedimentation of the fibers, which also may lead in some extent to the inhibition of the silica gelation [55]. In this case, special care should be taken in the control of the kinetic of the sol-gel reaction, namely the immersing time of the fibers in the solution [55]. On the contrary, the reinforcing through a fiber blanket can be provided simply by immersing the fiber blanket inside of the sol before gelation, facilitating large scale production [176,177]. Overall, the reinforcing of silica aerogels with fiber networks is more costly than reinforcement of silica aerogels with polymers, since the starting materials and organic monomers are normally cheaper than the fibers.

\section{Outlook and future prospects}

Tailoring the underlying silica backbone structures with more flexible silica precursors, compounding the three-dimensional network of silica structure with different polymeric systems and integrating a low percentage of different fibers in the silica network, improves not only the strength of the aerogels, but also, in most cases, their elasticity [32]. In general, increasing the amount of polymer cross-linker leads to a dense and highly stiff structure of silica and weakens the thermal insulation properties [161]. Thus, in this case, optimized polymer concentrations, in combination with alterations made in the silica backbone structure, should increase flexibility and strength with only slight differences in other properties like density and thermal insulation properties. In this sense, implementing one pot surface initiation polymerization from the surface of the secondary silica particles, or doing polymerization with well controlled polymerization techniques can be effective to strengthen the aerogels without significantly increasing in their density $[24,49,161]$.

Thus, in the present report, we have elucidated firstly the synthesis chemistry and processing and different drying techniques to obtain silica aerogels; secondly, we summarized different recent strategies for fabricating silica aerogels with improved mechanical properties.

Mechanically strong and low density monolithic aerogels have potential to be widely used in space and armor applications as thermal insulators. However, namely in the field of polymer reinforced aerogels, additional work is still required to produce aerogels at commercial scale with certain configurations such as flexible thin sheets. In thin film shape, the polymer-reinforced aerogels with flexible linking groups would probably be too fragile to stand on their own shapes. The recent bendable and flexible thin sheet processed by fiber incorporation in silica aerogels is an efficient candidate for insulating system, and could provide the requirement of folding or wrapping around different space assemblages that are needed for thermal insulation [55]. One interesting recent research is the development of smart silica aerogels. Synthesis of shape memory aerogels by means of a shape memory polymer as reinforcement agent is a promising area of investigation [60]. For instance, a polyurethane block copolymer as a shape memory polymer can be used as reinforcing agent for the silica aerogel network [60]. This polymeric system is able to change its shape in response to external stimuli. So taking advantage of this smart behavior, the aerogels can be stored in deformed state for transport aboard a spacecraft.

\section{Acronyms}

$\begin{array}{ll}\text { ATRP } & \text { Atom Transfer Radical Polymerization } \\ \text { AIBN } & 2,2^{\prime} \text {-Azobis(2-methylpropionitrile) } \\ \text { ALD } & \text { Atomic Layer Deposition } \\ \text { CVD } & \text { Chemical Vapor Deposition } \\ \text { DoE } & \text { Design of Experiments } \\ \text { EVA } & \text { Extra-Vehicular Activity } \\ \text { EDL } & \text { Entry, Descent, and Landing } \\ \text { ORMOSIL } & \text { Organically Modified Silica } \\ \text { PDMS } & \text { Polydimethylsiloxane } \\ \text { PMMA } & \text { Polymethylmethacrylate } \\ \text { PDVB } & \text { Polydivinylbenzene } \\ \text { PS } & \text { Polystyrene } \\ \text { PU } & \text { Polyurethane } \\ \text { SFD } & \text { Supercritical Fluid Drying } \\ \text { SEM } & \text { Scanning Electron Microscopy } \\ \text { TEOS } & \text { Tetraethylorthosilicate } \\ \text { TMOS } & \text { Tetramethylorthosilicate } \\ \text { TMCS } & \text { Trimethylchlorosilane }\end{array}$

\section{List of common organosilanes used in this article}

Monofunctional organosilanes of the type $\mathrm{RSiX}_{3}$ :

$\begin{array}{ll}\text { APTES } & \text { Aminopropyltriethoxysilane } \\ \text { ETMS } & \text { Ethyltrimethoxysilane } \\ \text { MTMS } & \text { Methyltrimethoxysilane } \\ \text { MTES } & \text { Methyltriethoxysilane } \\ \text { VTMS } & \text { Vinyltrimethoxysilane } \\ \text { VTES } & \text { Vinyltriethoxysilane }\end{array}$

Difunctional organosilane of the type $\mathrm{R}_{2} \mathrm{SiX}_{2}$ :

\section{DMDES Dimethyldiethoxysilane}

Bridged alkyl-linked organosilanes of the type $\mathrm{X}_{3} \mathrm{Si}-\mathrm{R}-\mathrm{SiX}_{3}$ :

BTSPD Bis[3-(triethoxysilyl)propyl]disulphide

BTMSH 1,6-Bis(trimethoxy silyl)hexane

BTMSPA Bis[3-(trimethoxysilyl)propyl)]amine

\section{Acknowledgments}

The research leading to these results has received funding from the European Union Seventh Framework Programme (FP7-MC-ITN) under 
Table A.1

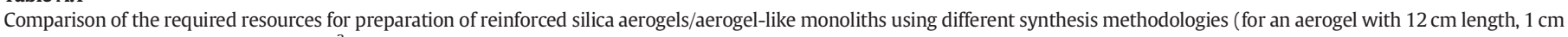
diameter and bulk density $\approx 0.3 \mathrm{~g} . \mathrm{cm}^{-3}$ ).

\begin{tabular}{|c|c|c|c|c|c|}
\hline \multicolumn{2}{|c|}{$\begin{array}{c}\text { Type of reinforced } \\
\text { silica }\end{array}$} & $\begin{array}{c}\text { Silica precursors/ } \\
\text { Other starting } \\
\text { materials }\end{array}$ & $\begin{array}{l}\text { Total time } \\
\text { for } \\
\text { preparation } \\
\text { (Days) }\end{array}$ & $\begin{array}{l}\text { Solvent for post- } \\
\text { gelation washing } \\
\text { and/or monomer } \\
\text { diffusion (Liter) }\end{array}$ & Drying methods \\
\hline \multicolumn{2}{|c|}{$\begin{array}{l}\text { Polymer reinforced } \\
\text { aerogel-like material } \\
\text { (xerogel) }\end{array}$} & $\begin{array}{c}\text { Main precursor: } \\
4.5 \mathrm{~mL} \\
\text { Surface modifier }{ }^{\mathrm{a}} \text { : } \\
1.5 \mathrm{~mL} \\
\text { Monomer: } 5 \mathrm{~g}\end{array}$ & $\approx 5$ days & $\approx 1 \mathrm{~L}$ & $\begin{array}{l}\text { Ambient pressure drying in } \\
\text { an oven: } \\
\text { a) Electricity - 2-3 days }\end{array}$ \\
\hline \multicolumn{2}{|c|}{$\begin{array}{l}\text { Class I hybrid } \\
\text { aerogels }\end{array}$} & $\begin{array}{l}\text { Main precursor: } \\
\quad 4.5 \mathrm{~mL} \\
\text { Monomer: } 5 \mathrm{~g}\end{array}$ & $\approx 5$ days & $\approx 0.5 \mathrm{~L}$ & $\begin{array}{l}\text { SFD: } \\
\text { a) Electricity }-4-5 \mathrm{~h} \text {; } \\
\text { b) } \mathrm{CO}_{2}-50 \mathrm{~L}(\mathrm{STP}) \\
\text { c) Solvent }-120 \mathrm{~mL}\end{array}$ \\
\hline \multirow{3}{*}{$\begin{array}{l}\text { Class II } \\
\text { hybrid } \\
\text { aerogels }\end{array}$} & $\begin{array}{l}\text { Multi-step } \\
\text { synthesis }\end{array}$ & $\begin{array}{c}\text { Main precursor: } \\
4.5 \mathrm{~mL} \\
\text { Surface modifier }{ }^{\mathrm{a}} \text { : } \\
1.5 \mathrm{~mL} \\
\text { Monomer: } \sim 10 \mathrm{~g}\end{array}$ & $\approx 5$ days & $\approx 1 \mathrm{~L}$ & $\begin{array}{l}\text { SFD: } \\
\text { a) Electricity - } 4-5 \mathrm{~h} \text {; } \\
\text { b) } \mathrm{CO}_{2}-50 \mathrm{~L}(\mathrm{STP}) \\
\text { c) Solvent }-120 \mathrm{~mL}\end{array}$ \\
\hline & $\begin{array}{l}\text { One pot } \\
\text { synthesis }\end{array}$ & $\begin{array}{c}\text { Main precursor: } \\
4.5 \mathrm{~mL} \\
\text { Surface modifier }{ }^{\mathrm{a}} \text { : } \\
1.5 \mathrm{~mL} \\
\text { Monomer: } 5 \mathrm{~g}\end{array}$ & $\approx 3$ days & $\approx 0.5 \mathrm{~L}$ & $\begin{array}{l}\text { SFD: } \\
\text { a) Electricity - } 4-5 \mathrm{~h} \text {; } \\
\text { b) } \mathrm{CO}_{2}-50 \mathrm{~L}(\mathrm{STP}) \\
\text { c) Solvent - } 120 \mathrm{~mL}\end{array}$ \\
\hline & Gas phase & $\begin{array}{c}\text { Main precursor: } \\
4.5 \mathrm{~mL} \\
\text { Surface modifier }{ }^{\mathrm{a}} \text { : } \\
1.5 \mathrm{~mL} \\
\text { Monomer: } 5 \mathrm{~g}\end{array}$ & $\approx 4$ days & $\approx 0.1 \mathrm{~L}$ & $\begin{array}{l}\text { SFD: } \\
\text { a) Electricity - } 4-5 \mathrm{~h} \text {; } \\
\text { b) } \mathrm{CO}_{2}-50 \mathrm{~L}(\mathrm{STP}) \\
\text { c) Solvent - } 120 \mathrm{~mL}\end{array}$ \\
\hline
\end{tabular}

${ }^{a}$ It is assumed that the silica surface modifier contributes $20 \mathrm{~mol} \%$ to the total silicon.

grant agreement No. 264710. The authors would like to thank the Directorate-General for Science, Research and Development of the European Commission for financial support of the research.

\section{Appendix A}

Table A.1 presents a comparison of the required resources for the production of an aerogel or an aerogel-like material of silica using several polymer-reinforcing methodologies, considering a given size/shape of the monolith and approximately the same bulk density. This table may be useful to estimate the cost inherent to each of these methodologies and to choose a certain route according with the existent resources. It should also be noted that due to the non-consistency between the extracted synthesis/processing/drying information in the literature, the data presented in this table is defined for the production of lab scale aerogels with the conditions that are optimized within the authors' research group.

\section{References}

[1] C.E. Carraher Jr., General topics: silica aerogels-properties and uses, Polym. News 30 (2005) 386-388.

[2] J.M. Schultz, K.I. Jensen, F.H. Kristiansen, Super insulating aerogel glazing, Sol. Energy Mater. Sol. Cells 89 (2005) 275-285.

[3] J.P. da Cunha, F. Neves, M.I. Lopes, On the reconstruction of Cherenkov rings from aerogel radiators, Nucl. Instrum. Methods A 452 (2000) 401-421.

[4] V. Wittwer, Development of aerogel windows, J. Non-Cryst. Solids 145 (1992) 233-236.

[5] V. Gibiat, O. Lefeuvre, T. Woignier, J. Pelous, J. Phalippou, Acoustic properties and potential applications of silica aerogels, J. Non-Cryst. Solids 186 (1995) 244-255.

[6] J.W. Long, K.E. Swider Lyons, R.M. Stroud, D.R. Rolison, Design of pore and matter architectures in manganese oxide charge-storage materials, Electrochem. Solid-State Lett. 3 (2000) 453-456

[7] D.A. Ward, E.I. Ko, Preparing catalytic materials by the sol-gel method, J. Ind. Eng. Chem. Res. 34 (1995) 421-433.

[8] C.T. Wang, C.L. Wu, I.C. Chen, Y.H. Huang, Humidity sensors based on silica nanoparticle aerogel thin films, Sens. Actuators B 107 (2005) 402-410.
[9] M.L.N. Perdigoto, R.C. Martins, N. Rocha, M.J. Quina, L. Gando-Ferreira, R. Patrício, L. Durães, Application of hydrophobic silica based aerogels and xerogels for removal of toxic organic compounds from aqueous solutions, J. Colloid Interface Sci. 380 (2012) 134-140.

[10] S.M. Jones, Aerogel: space exploration applications, J. Sol-Gel Sci. Technol. 40 (2006) 351-357.

[11] H.H. Tang, E.S. Orndoff, L.A. Trevino, 36th International Conference on Environment Systems, Norfolk, American Institute of Aeronautics and Astronautics, Reston, 2006, p. 2235.

[12] H.L. Paul, K.R. Diller, Pressure wave propagation in fluid-filled co-axial elastic tubes. Part 2: mechanisms for the pathogenesis of syringomyelia, J. Biomech. Eng. 125 (2003) 639-647.

[13] J.A. Del Corso, W.E. Bruce, K.A. Liles, S.J.Hughes, 20th AIAA Aerodynamic Decelerator Systems Technology Conference and Seminar, Seattle, American Institute of Aeronautics and Astronautics, Reston, 2009, pp. 2009-2925.

[14] M.T. Guise, B. Hosticka, B.C. Earp, P.M. Norris, An experimental investigation of aerosol collection utilizing packed beds of silica aerogel microspheres, J. Non-Cryst. Solids 285 (1995) 317-322.

[15] L.W. Hrubesh, Aerogel applications, J. Non-Cryst. Solids 225 (1998) 335-342.

[16] M. Schmidt, F. Schwertfeger, Applications for silica aerogel products, J. Non-Cryst. Solids 225 (1998) 364-368.

[17] M.M. Moner-Girona, E.A. Roig, J. Esteve, E. Molins, Sol-gel processing parameters and carbon addition, J. Non-Cryst. Solids 285 (2001) 1-3.

[18] A.V. Rao, D. Haranath, Effect of methyltrimethoxysilane as a synthesis component on the hydrophobicity and some physical properties of silica aerogels, Microporous Mesoporous Mater. 30 (1999) 267-273.

[19] A.V. Rao, S.D. Bhagat, H. Hirashima, G.M. Pajonk, Synthesis of flexible silica aerogels using methyltrimethoxysilane (MTMS) precursor, J. Colloid Interface Sci. 300 (2006) 279-285.

[20] D.Y. Nadargi, S.S. Latthe, H. Hirashima, A.V. Rao, Studies on rheological properties of methyltriethoxysilane (MTES) based flexible superhydrophobic silica aerogels, Microporous Mesoporous Mater. 117 (2009) 617-626.

[21] H. Guo, B.N. Nguyen, L.S. Mccorkle, B. Shonkwilerb, M.A.B. Meador, Elastic low density aerogels derived from bis[3-(triethoxysilyl)propyl]disulfide, tetramethylorthosilicate and vinyltrimethoxysilane via a two-step process, J. Mater. Chem. 19 (2009) 9054-9062.

[22] N. Leventis, A. Sadekar, N. Chandrasekaran, C. Sotiriou-Leventis, Click synthesis of monolithic silicon carbide aerogels from polyacrylonitrile-coated 3D silica networks, Chem. Mater. 22 (2010) 2790-2803.

[23] M.A.B. Meador, L.A. Capadona, L. Mccorkle, D.S. Papadopoulos, N. Leventis, Structure-property relationships in porous 3D nanostructures as a function of preparation conditions: isocyanate cross-linked silica aerogels, Chem. Mater. 19 (2007) 2247-2260.

[24] D.J. Boday, P.Y. Keng, B. Muriithi, J. Pyun, D.A. Loy, Mechanically reinforced silica aerogel nanocomposites via surface initiated atom transfer radical polymerizations, J. Mater. Chem. 20 (2010) 6863-6865. 
[25] D.J. Boday, R.J. Stover, B. Muriithi, M.W. Keller, J.T. Wertz, K.A.D. Obrey, D.A. Loy, Strong, low-density nanocomposites by chemical vapor deposition and polymerization of cyanoacrylates on aminated silica aerogels, ACS Appl. Mater. Interfaces 1 (2009) 1364-1369.

[26] N. Leventis, Three dimensional core-shell superstructures: mechanically strong aerogels, Acc. Chem. Res. 40 (2007) 874-884.

[27] M.A.B. Meador, S.L. Vivod, L. Mccorkle, D. Quade, R.M. Sullivan, L.N. Ghson, N. Clark, L.A. Capaclona, Reinforcing polymer cross-linked aerogels with carbon nanofibers, J. Mater. Chem. 18 (2008) 1843-1852.

[28] N. Leventis, C. Sotiriou-Leventis, G. Zhang, A.-M.M. Rawashdeh, Nanoengineering strong silica aerogels, Nano Lett. 2 (2002) 957-960.

[29] J.P. Randall, M.A.B. Meador, S.C. Jana, Tailoring mechanical properties of aerogels for aerospace applications, ACS Appl. Mater. Interfaces 3 (2011) 613-626.

[30] N.C. Holmes, H.B. Radousky, M.J. Moss, W.J. Nellis, S. Henning, Silica at ultrahigh temperature and expanded volume, Appl. Phys. Lett. 45 (1984) 626-628.

[31] P. Tsou, Silica aerogel captures cosmic dust intact, J. Non-Cryst. Solids 186 (1995) 415-427.

[32] In: N. Leventis, H. Lu, M.M. Koebel (Eds.), Aerogel Handbook, Springer, 2010, pp. 315-334.

[33] S.L. Vivod, M.A.B. Meador, B.N. Nguyen, R. Perry, Flexible di-isocyanate cross-linked silica aerogels with 1,6-bis(trimethoxysilyl)hexane incorporated in the underlying silica backbone, Polym. Prepr. 50 (2009) 119-120.

[34] S.J. Kramer, F. Rubio-Alonso, J.D. Mackenzie, Organically modified silicate aerogels, "Aeromosils", Mater. Res. Soc. Symp. Proc. 435 (1996) 295-300.

[35] D.A. Loy, K.J. Shea, Bridged polysilsesquioxanes: highly porous hybrid organicinorganic materials, Chem. Rev. 95 (1995) 1431-1442.

[36] J. Fricke, Aerogels - highly tenuous solids with fascinating properties, J. Non-Cryst. Solids 100 (1988) 169-173.

[37] R.W. Pekala, L.W. Hrubesh, T.M. Tillotson, C.T. Alviso, J.F. Poco, J.D. Lemay, MRS Symposium W: Scaling in Disordered Materials, Boston, November, Materials Research Society, Warrendale, PA, 1990.

[38] J. Fricke, A. Emmerling, Aerogels-recent progress in production techniques and novel applications, J. Sol-Gel Sci. Technol. 13 (1998) 299-303.

[39] J. Gross, J. Fricke, Scaling of elastic properties in highly porous nanostructured aerogels, J. Nanostruct. Mater. 6 (1995) 905.

[40] T. Woignier, J. Reynes, A. Hafidialaoui, I. Beurroies, J. Phalippou, Different kinds of structure in aerogels: relationships with the mechanical properties, J. Non-Cryst. Solids 241 (1998) 45-52.

[41] A.C. Pierre, Introduction to Sol-Gel Processing, Kluwer Academic Publishers, Boston, 1998.

[42] C.J. Brinker, G.W. Scherer, Sol-Gel Science: The Physics and Chemistry of Sol-Gel Processing, Academic Press, 1990.

[43] A.C. Pierre, G.M. Pajonk, Aerogels and their applications, Chem. Rev. 102 (2002) 4243-4265.

[44] A.P. Ambekar, P. Bagade, A review on: “aerogel - world's lightest solid", Pop. Plast. Packag. 51 (2006) 96-102.

[45] L. Kocon, J. Phalippou, Aerogels. Material aspect Techniques de l'Ingenieur, Sci. Fondam. AF196 (2005)(AF3610/3611-AF3610/3621).

[46] G.M. Pajonk, Some applications of silica aerogels, Colloid Polym. Sci. 281 (2003) 637-651.

[47] A. Soleimani Dorcheh, M.H. Abbasi, Silica aerogel; synthesis, properties and characterization, J. Mater. Proc. Technol. 199 (2008) 10-26.

[48] M.A.B. Meador, E.F. Fabrizzio, F. Ilhan, A. Dass, G. Zhang, P. Vassilaras, J.C. Johnston, N. Leventis, Crosslinking amine modified silica aerogels with epoxies: mechanically strong lightweight porous materials, Chem. Mater. 17 (2005) 1085-1098.

[49] M.A.B. Meador, B.N. Nguyen, D. Quade, S.L. Vivod, Epoxy reinforced aerogels made using a streamlined process, ACS Appl. Mater. Interfaces 2 (2010) 2162-2168.

[50] J.K. Lee, G.L. Gould, W. Rhine, Polyurea based aerogel for a high performance thermal insulation material, J. Sol-Gel Sci. Technol. 49 (2009) 209-220.

[51] L.A. Capadona, M.A.B. Meador, A. Alunni, E.F. Fabrizio, P. Vassilaras, N. Leventis, Effect of processing conditions on chemical make-up of di-isocyanate crosslinked silica aerogels, Polymer 47 (2006) 5754-5761.

[52] B.N. Nguyen, M.A.B. Meador, M.E. Tousley, B. Shonkwiler, L. Mccorkle, D.A Scheiman, A. Palczer, Tailoring elastic properties of silica aerogels cross-linked with polystyrene, ACS Appl. Mater. Interfaces 1 (2009) 621-630.

[53] U.F. Ilhan, E.F. Fabrizio, L. Mccorkle, D.A. Scheiman, A. Dass, A. Palczer, M.A.B. Meador, J.C. Johnston, N. Leventis, Hydrophobic monolithic aerogels by nanocasting polystyrene on amine-modified silica, J. Mater. Chem. 16 (2006) 3046-3054.

[54] In: N. Leventis, H. Lu, M.M. Koebel (Eds.), Aerogel Handbook, Springer, 2010, pp. 252-285.

[55] L. Li, B. Yalcin, B.N. Nguyen, M.A.B. Meador, M. Cakmak, Flexible nanofiber reinforced aerogel (xerogel): synthesis, manufacture and characterization, ACS Appl. Mater. Interfaces 1 (2009) 2491-2501.

[56] C.J. Stepanian, G.L. Gould, R. Begag, Aerogel composite with fibrous batting, US Patent 7,078,359 B2, (2002).

[57] Z. Zhang, J. Shen, X. Ni, G. Wu, B. Zhou, M. Yang, X. Gu, M. Qian, Y. Wu, Hydrophobic silica aerogels strengthened with nonwoven fibers, Macromol. Sci. A 43 (2006) 1663-1670.

[58] A. Karout, P. Buisson, A. Perrard, A.C. Pierre, Shaping and mechanical reinforcement of silica aerogel biocatalysts with ceramic fiber felts, J. Sol-Gel Sci. Technol. 36 (2005) 163-171.

[59] Z. Zhihua, S. Jun, N. Xingyuan, L. Yang, W. Jichao, W. Guangming, Z. Bin, W. Guoqing, W. Peiqing, W. Qingfeng, N. Xixian, Mechanical reinforcement of silica aerogel insulation with ceramic fibers, Nanoelectronics Conference, INEC, 2nd IEEE International, 2008, pp. 371-374.
[60] S.C. Jana, M.A.B. Meador, J.P. Randall, Process for forming shape-memory polymer aerogel composites, US Patent 0144962, (2010).

[61] In: N. Leventis, H. Lu, M.M. Koebel (Eds.), Aerogels Handbook, Springer, 2010, pp. 21-45.

[62] S.S. Kistler, Coherent expanded aerogels and jellies, Nature 127 (1931) 741-741.

[63] S.S. Kistler, Coherent expanded aerogels, J. Phys. Chem. 36 (1932) 52-64.

[64] C.J. Lee, G.S. Kim, S.H. Hyun, Synthesis of silica aerogels from waterglass via new modified ambient drying, J. Mater. Sci. 37 (2002) 2237-2241.

[65] G. Nicolaon, S. Teichner, New preparation process for silica xerogels and aerogels, and their textural properties, Bull. Soc. Chim. Fr. 5 (1968) 1900-1906.

[66] G. Wu, J. Wang, J. Shen, T. Yang, Q. Zhang, B. Zhou, Z. Deng, F. Bin, D. Zhou, F. Zhang, Properties of sol-gel derived scratch-resistant nano-porous silica films by a mixed atmosphere treatment, J. Non-Cryst. Solids 275 (2000) 169-174.

[67] C. Alié, F. Ferauche, R. Pirard, A.-J. Lecloux, J.-P. Pirard, Preparation of low-density xerogels by incorporation of additives during synthesis, J. Non-Cryst. Solids 289 (2001) 88-96.

[68] F. Kirkbir, H. Murata, D. Meyers, S. Ray Chaudhuri, A. Sarkar, Drying and sintering of sol-gel derived large $\mathrm{SiO}_{2}$ monoliths, J. Sol-Gel Sci. Technol. 6 (1996) 203-217.

[69] X. Zhang, S. Huang, Single step on-column frit making for capillary high-performance liquid chromatography using sol-gel technology, J. Chromatogr. 910 (2001) 13-18.

[70] A.P. Rao, A.V. Rao, J.L. Gurav, Effect of protic solvents on the physical properties of the ambient pressure dried hydrophobic silica aerogels using sodium silicate precursor, J. Porous. Mater. 15 (2008) 507-512.

[71] B. Karmakar, G. De, D. Ganguli, Dense silica microspheres from organic and inorganic acid hydrolysis of TEOS, J. Non-Cryst. Solids 272 (2000) 119-126.

[72] L. Durães, M. Ochoa, A. Portugal, N. Duarte, J.P. Dias, N. Rocha, J. Hernandez, Tailored silica based xerogels and aerogels for insulation in space environments, Adv. Sci. Technol. 63 (2010) 41-46.

[73] A.-M. Siouffi, Silica gel-based monoliths prepared by the sol-gel method: facts and figures, J. Chromatogr. A 1000 (2003) 801-818.

[74] P.B. Wagh, A.V. Rao, D. Haranath, Influence of molar ratios of precursor, solvent and water on physical properties of citric acid catalyzed TEOS silica aerogels, Mater. Chem. Phys. 5 (1998) 41-47.

[75] S.D. Bhagat, A.V. Rao, Surface chemical modification of TEOS based silica aerogels synthesized by two step (acid-base) sol-gel process, Appl. Surf. Sci. 252 (2006) 4289-4297.

[76] A.V. Rao, G.M. Pajonk, S.D. Bhagat, Comparative studies on the surface chemical modification of silica aerogels based on various organosilane compounds of the type RnSiX4 - n, J. Non-Cryst. Solids 350 (2004) 216-223.

[77] A. Jitianu, A. Britchi, C. Deleanu, V. Badescu, M. Zaharescu, Comparative study of the sol-gel processes starting with different substituted Si-alkoxides, J. Non-Cryst. Solids 319 (2003) 263-279.

[78] In: N. Leventis, H. Lu, M.M. Koebel (Eds.), Aerogel Handbook, Springer, 2010, pp. 79-100.

[79] L. Durães, S. Nogueira, A. Santos, C. Preciso, J. Hernandez, A. Portugal, Flexible silica based xerogels and aerogels for spatial applications, in: E. Ferreira (Ed.), Proc. of the 10th International Chemical and Biological Engineering Conference-CHEMPOR Department of Biological Engineering of University of Minho, Braga, 2008, p. 563.

[80] M. Ochoa, L. Duraes, A.M. Beja, A. Portugal, Study of the suitability of silica based xerogels synthesized using ethyltrimethoxysilane and/or methyltrimethoxysilane precursors for aerospace applications, J. Sol-Gel Sci. Technol. 61 (2012) 151-160.

[81] G. Schottner, Hybrid sol-gel-derived polymers: applications of multifunctional materials, Chem. Mater. 13 (2001) 3422-3435.

[82] A.V. Rao, N.D. Hegde, H. Hirashima, Absorption and desorption of organic liquids in elastic superhydrophobic silica aerogels, J. Colloid Interface Sci. 305 (2007) 124-132.

[83] K.J. Shea, D.A. Loy, Bridged polysilsesquioxanes. Molecular-engineered hybrid organic-inorganic materials, Chem. Mater. 13 (2001) 3306-3319.

[84] G. Zhang, A. Dass, A.-M.M. Rawashdeha, J. Thomas, J.A. Counsil, C. Sotiriou-Leventis E.F. Fabrizio, F. Ilhan, P. Vassilaras, D. Scheiman, L. Mccorkle, A. Palczer, J.C. Johnston, M.A.B. Meador, N. Leventis, Isocyanate-crosslinked silica aerogel monoliths: preparation and characterization, J. Non-Cryst. Solids 350 (2004) 152-164.

[85] E.J.A. Pope, J.D. Mackenzie, Structural studies of silica-aerogel - a mass-fractal model system, J. Non-Cryst. Solids 87 (1986) 185.

[86] C.J. Brinker, K.D. Keefer, D.W. Schaefer, R.A. Assink, B.D. Kay, C.S. Ashley, Sol-gel transition in simple silicates, J. Non-Cryst. Solids 63 (1984) 45-59.

[87] M. Einasrud, M. Dahle, S. Lima, S. Hæreid, Preparation and properties of monolithic silica xerogels from TEOS-based alcogels aged in silane solutions, J. Non-Cryst. Solids 186 (1995) 96-103.

[88] J. Estella, J.C. Echeverria, M. Laguna, J. Garrido, Effects of aging and drying conditions on the structural and textural properties of silica gels, Microporous Mesoporous Mater. 102 (2007) 274-282.

[89] R.A. Strom, Y. Masmoudi, A. Rigacci, G. Petermann, L. Gullberg, B. Chevalier, M.-A Einarsrud, Strengthening and aging of wet silica gels for up-scaling of aerogel preparation, J. Sol-Gel Sci. Technol. 41 (2007) 291-298.

[90] M.-A. Einarsrud, E. Nilsena, A. Rigacci, G.M. Pajonk, S. Buathier, D. Valette, M. Durant B. Chevalier, P. Nitz, F. Ehrburger-Dolle, Strengthening of silica gels and aerogels by washing and aging processes, J. Non-Cryst. Solids 285 (2001) 1-7.

[91] H. Hdach, T. Woignier, J. Phalippou, G.W. Scherer, Effect of aging and pH on the modulus of aerogels, J. Non-Cryst. Solids 121 (1990) 202-205.

[92] D.Y. Nadargi, S.S. Latthe, A.V. Rao, Effect of post-treatment (gel aging) on the properties of methyltrimethoxysilane based silica aerogels prepared by two-step sol-gel process, J. Sol-Gel Sci. Technol. 49 (2009) 53-59.

[93] A. Bisson, A. Rigacci, D. Lecomte, E. Rodier, P. Achard, Drying of silica gels to obtain aerogels: phenomenology and basic techniques, Dry. Technol. 21 (2003) 593-628.

[94] Y.D. Tretyakov, O.A. Shlyakhtin, Recent progress in cryochemical synthesis of oxide materials, J. Mater. Chem. 9 (1999) 19-24. 
[95] G.M. Pajonk, M. Repellin-Lacroix, S. Abouarnadasse, J. Chaouki, D. Klvana, From solgel to aerogels and cryogels, J. Non-Cryst. Solids 121 (1990) 66-67.

[96] F. Schwertfeger, D. Frank, M. Schmidt, Hydrophobic waterglass based aerogels without solvent exchange or supercritical drying, J. Non-Cryst. Solids 225 (1998) 24-29.

[97] M.A. Einarsrud, M.B. Kirkedelen, E. Nilsen, K. Mortensen, J. Samseth, Structural development of silica gels aged in TEOS, J. Non-Cryst. Solids 231 (1998) 10-16.

[98] C. Alié, N. Tcherkassova, F. Ferauche, S. Lambert, B. Heinrichs, R. Pirard, J.-P. Pirard, Multigram scale synthesis and characterization of low-density silica xerogels, J. Non-Cryst. Solids 352 (2006) 2763-2771.

[99] L. Durães, M. Ochoa, N. Rocha, R. Patrício, N. Duarte, V. Redondo, A. Portugal, Effect of the drying conditions on the microstructure of silica based xerogels and aerogels, J. Nanosci. Nanotechnol. 12 (2012) 6828-6834.

[100] L. Duffours, T. Woignier, J. Phalippou, Plastic behavior of aerogels under isostatic pressure, J. Non-Cryst. Solids 186 (1995) 321-327.

[101] D.L. Meixner, P.N. Dyer, Influence of sol-gel synthesis parameters on the microstructure of particulate silica xerogels, J. Sol-Gel Sci. Technol. 14 (1999) 223-232.

[102] M. Park, V.C. Menon, S. Komarneni, Ethanol washing effect on textural properties of the sodium-silicate derived silica xerogel, J. Sol-Gel Sci. Technol. 12 (1998) $15-20$.

[103] X. Wang, W. Li, G. Zhu, S. Qiu, D. Zhao, B. Zhong, Effects of ammonia/silica molar ratio on the synthesis and structure of bimodal mesopore silica xerogel, Microporous Mesoporous Mater. 71 (2004) 87-97.

[104] A. Karout, A.C. Pierre, Silica xerogels and aerogels synthesized with ionic liquids, J Non-Cryst. Solids 353 (2007) 2900-2909.

[105] G.W. Scherer, D.M. Smith, X. Qiu, J.M. Anderson, Compression of aerogels, J. Non-Cryst. Solids 186 (1995) 316-320.

[106] S.S. Prakash, C.J. Brinker, A.J. Hurd, S.M. Rao, Silica aerogel films prepared at ambient pressure by using surface derivatization to induce reversible drying shrinkage, Nature 374 (1995) 439-443.

[107] N.D. Hegde, A.V. Rao, Physical properties of methyltrimethoxysilane based elastic silica aerogels prepared by the two-stage sol-gel process, J. Mater. Sci. Lett. 42 (2007) 6965-6971.

[108] D.M. Smith, R. Deshpande, C.J. Brinker, Preparation of low-density aerogels at ambient pressure, Mater. Res. Soc. Symp. Proc. 271 (1992) 567-572.

[109] S.-W. Hwang, H.-H. Jung, S.-H. Hyun, Y.-S. Ahn, Effective preparation of crack-free silica aerogels via ambient drying. J. Sol-Gel Sci. Technol. 41 (2007) 139-146.

[110] C.E. Kim, J.S. Yoon, H.J. Hwang, Synthesis of nanoporous silica aerogel by ambient pressure drying, J. Sol-Gel Sci. Technol. 49 (2009) 47-52.

[111] S.D. Bhagat, Y.-H. Kim, M.-J. Moon, Y.-S. Ahn, J.-G. Yeo, A cost-effective and fast synthesis of nanoporous $\mathrm{SiO}_{2}$ aerogel powders using water-glass via ambient pressure drying route, Solid State Sci. 9 (2007) 628-635.

[112] A.M. Kartal, C. Erkey, Surface modification of silica aerogels by hexamethyldisilazanecarbon dioxide mixtures and their phase behavior, J. Supercrit. Fluids 53 (2010) $115-120$.

[113] A.P. Rao, A.V. Rao, G.M. Pajonk, Hydrophobic and physical properties of the ambient pressure dried silica aerogels with sodium silicate precursor using various surface modification agents, Appl. Surf. Sci. 253 (2007) 6032-6040.

[114] T. Adachi, S. Sakka, Effect of formamide additive on the chemistry of silica sol-gels: part I: NMR of silica hydrolysis, J. Non-Cryst. Solids 79 (1986) 177-194.

[115] F.A.L. Dullien, Porous Media: Fluid Transport and Pore Structure, Academic Press, San Diego, 1992.

[116] P.H. Tewari, A.J. Hunt, K.D. Lofftus, Ambient-temperature supercritical drying of transparent silica aerogels, Mater. Lett. 63 (1985) 363-367.

[117] M.J. Bommel, A.B. De Haan, Drying of silica aerogel with supercritical carbon dioxide, J. Non-Cryst. Solids 186 (1995) 78-82.

[118] F. Kirkbir, H. Murata, D. Meyers, S.R. Chaudhuri, Drying of aerogels in different solvents between atmospheric and supercritical pressures, J. Non-Cryst. Solids 225 (1998) 14-18.

[119] N. Leventis, H. Lu, in: M.M. Koebel (Ed.), Aerogel Handbook, Springer, 2010, pp. $56-57$.

[120] J.H. She, T. Ohji, Porous mullite ceramics with high strength, J. Mater. Sci. Lett. 31 (2002) 1833-1834

[121] H.-S. Ma, A.P. Roberts, J.-H. Prevost, R. Jullien, G.W. Scherer, Mechanical structureproperty relationship of aerogels, J. Non-Cryst. Solids 277 (2000) 127-141.

[122] S. Hæreid, J. Anderson, M.A. Einarsrud, D.W. Hua, D.M. Smith, Thermal and temporal aging of TMOS based aerogel precursors in water, J. Non-Cryst. Solids 185 (1995) 221-226.

[123] E.M. Lucas, M.S. Doescher, D.M. Ebenstein, K.J. Wald, D.R. Rolison, Silica aerogels with enhanced durability, 30-nm mean pore-size, and improved immersibility in liquids, J. Non-Cryst. Solids 350 (2004) 244-252.

[124] H.H. Huang, B. Orler, G.L. Wilkes, Structure-property behavior of new hybrid materials incorporating oligomeric species into sol-gel glasses. 3. Effect of acid content, tetraethoxysilane content, and molecular weight of poly(dimethylsiloxane), Macromolecules 20 (1987) 1322-1330.

[125] T.-J. Yim, S.Y. Kim, K.-P. Yoo, Fabrication and thermophysical characterization of nano-porous silicapolyurethane hybrid aerogels by sol-gel processing and supercritical solvent drying technique, Korean J. Chem. Eng. 19 (2002) 159-166.

[126] B. Yuan, S. Ding, D. Wang, G. Wang, H. Li, Heat insulation properties of silic aerogel/glass fiber composites fabricated by press forming, Mater. Lett. 75 (2012) 204-206.

[127] X. Lu, R. Caps, J. Fricke, C.T. Alviso, R.W. Pekala, Correlation between structure and thermal conductivity of organic aerogels, J. Non-Cryst. Solids 188 (1995) 226-234.

[128] A.V. Rao, M.M. Kulkarni, G.M. Pajonk, D.P. Amalnerkar, T. Seth, Synthesis and characterization of hydrophobic silica aerogels using trimethylethoxysilane as a co-precursor, J. Sol-Gel Sci. Technol. 27 (2003) 103-109.
[129] K. Kanamori, M. Aizawa, K. Nakanishi, T. Hanada, New transparent methylsilsesquioxane aerogels and xerogels with improved mechanical properties, Adv. Mater. 19 (2007) 1589-1593.

[130] D.Y. Nadargi, A.V. Rao, Methyltriethoxysilane: new precursor for synthesizing silica aerogels, J. Alloy Compd. 467 (2009) 397-404.

[131] P.R. Aravind, G.D. Soraru, High surface area methyltriethoxysilane-derived aerogels by ambient pressure drying, J. Porous. Mater. 18 (2011) 159-165.

[132] A.V. Rao, S.D. Bhagat, Synthesis and physical properties of TEOS based silica aerogels prepared by two step (acid-base) sol-gel process, Solid State Sci. 6 (2004) 945-952.

[133] H. Schmidt, New type of non-crystalline solids between inorganic and organic materials, J. Non-Cryst. Solids 73 (1985) 681-691.

[134] D.S. Ravaine, Y. Charbouillot, M. Vincens, A new family of organically modified silicates prepared from gels, J. Non-Cryst. Solids 82 (1986) 210-219.

[135] L. Mascia, Developments in organic-inorganic polymeric hybrids: ceramers, Trends Polym. Sci. 3 (1995) 61-66.

[136] R.A. Nass, W. Glaubitt, H. Schmidt, Modelling of ORMOCER coatings by processing, J. Non-Cryst. Solids 121 (1990) 370-374.

[137] D.A. Loy, G.M. Jamison, B.M. Baugher, A.S. Myers, R.A. Assink, K.J. Shea, Sol-gel synthesis of hybrid organic-inorganic materials. Hexylene- and phenylene-bridged polysiloxanes, Chem. Mater. 8 (1996) 656-663.

[138] M.A.B. Meador, A.S. Weber, A. Hindi, M. Naumenko, L Mccorkle, D. Quade, S.L Vivod, G.L. Gould, S. White, K. Deshpande, Structure-property relationships in porous 3D nanostructures: epoxy-cross-linked silica aerogels produced using ethanol as the solvent, ACS Appl. Mater. Interfaces 1 (2009) 894-906.

[139] K.J. Shea, D.A. Loy, A mechanistic investigation of gelation. The sol-gel polymerization of precursors to bridged polysilsesquioxanes, Acc. Chem. Res. 34 (2001) 707-716.

[140] S.L. Vivod, M.A.B. Meador, B.N. Nguyen, D.J. Quade, J.P. Randall, Di-isocyanate crosslinked aerogels with 1,6-bis(trimethoxysilyl)hexane incorporated in silica backbon, The 236th ACS National Meeting, Philadelphia, 2008.

[141] C. Sanchez, B. Julia, P. Belleville, M. Popall, Applications of hybrid organic-inorganic nanocomposites, J. Mater. Chem. 15 (2005) 3559-3592.

[142] C. Sanchez, F. Ribot, B. Lebeau, Molecular design of hybrid organic-inorganic nanocomposites synthesized via sol-gel chemistry, J. Mater. Chem. 9 (1999) 35-44.

[143] C. Sanchez, P. Bellevill, M. Popall, L. Nicolea, Applications of advanced hybrid organicinorganic nanomaterials: from laboratory to market, Chem. Soc. Rev. 40 (2011) 696-753.

[144] B.M. Novak, D. Auerbach, C. Verrier, Low-density, mutually interpenetrating organic-inorganic composite materials via supercritically drying techniques, Chem. Mater. 6 (1994) 282-286.

[145] G. Gould, D. Ou, R. Begag, W.E. Rhine, Highly-transparent polymer modified silica aerogels, Polym. Prepr. 49 (2008) 534-535.

[146] R. Reisfeld, Spectroscopy and applications of molecules in glasses, J. Non-Cryst. Solids 121 (1990) 254-266.

[147] J. Mckiernan, E. Simoni, B. Dunn, J.I. Zink, Proton diffusion in the pores of silicate sol-gel glasses, J. Phys. Chem. 98 (1994) 1006-1009.

[148] O.-H. Park, Y.-J. Eo, Y.-K. Choi, B.S. Bae, Preparation and optical properties of silica-poly(ethylene oxide) hybrid materials, J. Sol-Gel Sci. Technol. 16 (2000) 235-241.

[149] R. Takahashi, S. Sato, T. Sodesawa, M. Suzuki, K. Ogura, Preparation of microporous silica gel by sol-gel process in the presence of ethylene glycol oligomers, Bull. Chem. Soc. Jpn. 73 (2000) 765-774.

[150] K. Iwashita, K. Tadanaga, T. Minami, Water permeation properties of $\mathrm{SiO}_{2}-\mathrm{RSiO}_{3}$ ( $\mathrm{R}=$ methyl, vinyl, phenyl) thin films prepared by sol-gel method on nylon-6 substrate, J. Appl. Polym. Sci. 61 (1996) 2173-2177.

[151] X. Tong, T. Tang, Z. Feng, B. Huang, Preparation of polymer/silica hybrid through sol-gel method involving emulsion polymers: II. poly(ethyl acrylate) $/ \mathrm{SiO}_{2}, \mathrm{~J}$. Appl. Polym. Sci. 86 (2002) 3532-3536

[152] J.M. Lin, C.C.M. Ma, F.Y. Wang, H.D. Wu, S.C. Kuang, Thermal, mechanical and morphological properties of phenolic resin/silica hybrid ceramers, J. Polym. Sci. B Polym. Phys. 38 (2000) 1699-1706.

[153] K. Nakane, T. Yamashita, K. Iwakura, F. Suzuki, Properties and structure of poly(vinyl alcohol)/silica composites, J. Appl. Polym. Sci. 74 (1999) 133-138.

[154] A. Bandyopadhyay, M.D. Sarkar, A.K. Bhowmick, Poly(vinyl alcohol)/silica hybrid nanocomposites by sol-gel technique: synthesis and properties, J. Mater. Sci. 40 (2005) 5233-5241.

[155] D. Fragiadakis, P. Pissis, L. Bokobza, Modified chain dynamics in poly (dimethylsiloxane)/silica nanocomposites, J. Non-Cryst. Solids 352 (2006) 4969-4972.

[156] D. Fragiadakis, P. Pissis, Glass transition and segmental dynamics in poly (dimethylsiloxane)/silica nanocomposites studied by various techniques, J. Non-Cryst. Solids 353 (2007) 4344-4352.

[157] N. Leventis, A. Palczer, L. Mccorkle, Nanoengineered silica-polymer composite aerogels with no need for supercritical fluid drying, J. Sol-Gel Sci. Technol. 35 (2005) 99-105

[158] Y. Hu, J. Mackenzie, Rubber-like elasticity of organically modified silicates, J. Mater. Sci. 27 (1992) 4415-4420.

[159] H. Zou, S. Wu, J. Shen, Polymer/silica nanocomposites: preparation, characterization, properties, and applications, Chem. Rev. 108 (2008) 3893-3957.

[160] A. Katti, N. Shimpi, S. Roy, H. Lu, E.F. Fabrizio, A. Dass, L.A. Capadona, N. Leventis, Chemical, physical, and mechanical characterization of isocyanate cross-linked amine-modified silica aerogels, Chem. Mater. 18 (2006) 285-296.

[161] S. Mulik, C. Sotiriou-Leventis, G. Churu, H. Lu, N. Leventis, Cross-linking 3D assemblies of nanoparticles into mechanically strong aerogels by surface-initiated free-radical polymerization, Chem. Mater. 20 (2008) 5035-5046. 
[162] H. Yang, X. Kong, Y. Zhang, C. Wu, E. Cao, Mechanical properties of polymer-modified silica aerogels dried under ambient pressure, J. Non-Cryst. Solids 357 (2011) 3447-3453.

[163] H. Guo, M.A.B. Meador, L. Mccorkle, D.J. Quade, J. Guo, B. Hamilton, M. Cakmak, G. Sprowl, Polyimide aerogels cross-linked through amine functionalized polyoligomeric silsesquioxane, ACS Appl. Mater. Interfaces 3 (2011) 546-552.

[164] D.J. Boday, R.J. Stover, B. Muriithi, M.W. Keller, J.T. Wertz, K.A.D. Obrey, D.A. Loy, Formation of polycyanoacrylate-silica nanocomposites by chemical vapor deposition of cyanoacrylates on aerogels, Chem. Mater. 20 (2008) 2845-2847.

[165] M. Knez, K. Nielsch, L. Niinistö, Synthesis and surface engineering of complex nanostructures by atomic layer deposition, Adv. Mater. 19 (2007) 3425-3438.

[166] K.L. Choy, Chemical vapour deposition of coatings, Prog. Mater. Sci. 48 (2003) 57-170.

[167] B.N. Nguyen, M.A.B. Meador, A. Medoro, V. Arendt, J. Randall, L. Mccorkle, B. Shonkwiler, Elastic behavior of methyltrimethoxysilane based aerogels reinforced with tri-isocyanate, ACS Appl. Mater. Interfaces 2 (2010) 1430-1443.

[168] Y.-S. Ye, Y.-N. Chen, J.-S. Wang, J. Rick, Y.-J. Huang, F.-C. Chang, B.-J. Hwang, Versatile grafting approaches to functionalizing individually dispersed graphene nanosheets using RAFT polymerization and click chemistry, Chem. Mater. 24 (2012) 2987-2997.
[169] K. Matyjaszewski, Atom Transfer Radical Polymerization (ATRP): current status and future perspectives, Macromolecules 45 (2012) 4015-4039.

[170] J. K. Lee, U.S. Patent, 0,259,979 (2007).

[171] K.E. Parmenter, F. Milstein, Mechanical properties of silica aerogels, J. Non-Cryst. Solids 223 (1998) 179-189.

[172] D. Klemm, B. Heublein, H.P. Fink, A. Bohn, Cellulose: fascinating biopolymer and sustainable raw material, Angew. Chem. Int. Ed. Engl. 44 (2005) 3358-3393.

[173] K. Finlay, M.D. Gawryla, D.A. Schiraldi, Biologically based fiber-reinforced/clay aerogel composites, Ind. Eng. Chem. Res. 47 (2008) 615-619.

[174] J. Cai, S. Liu, J. Feng, S. Kimura, M. Wada, S. Kuga, L. Zhang, Cellulose-silica nanocomposite aerogels by in situ formation of silica in cellulose gel, Angew. Chem. Int. Ed. Engl. 51 (2012) 2076-2079.

[175] R.T. Olsson, M.A. Azizi Samir, G. Salazar-Alvarez, L. Belova, V. Strom, L.A. Berglund, O. Ikkala, J. Nogues, U.W. Gedde, Making flexible magnetic aerogels and stiff magnetic nanopaper using cellulose nanofibrils templates, Nat. Nanotechnol. 5 (2010) 584-588.

[176] XT@Pyrogel, Flexible Industrial Insulation for High-Temperature Applications, Aspen Aerogels, Inc., 2010. (http://www.aerogel.com).

[177] J. Chandradass, S. Kang, D.-S. Bae, Synthesis of silica aerogel blanket by ambient drying method using water glass based precursor and glass wool modified by alumina sol, J. Non-Cryst. Solids 354 (2008) 4115-4119. 